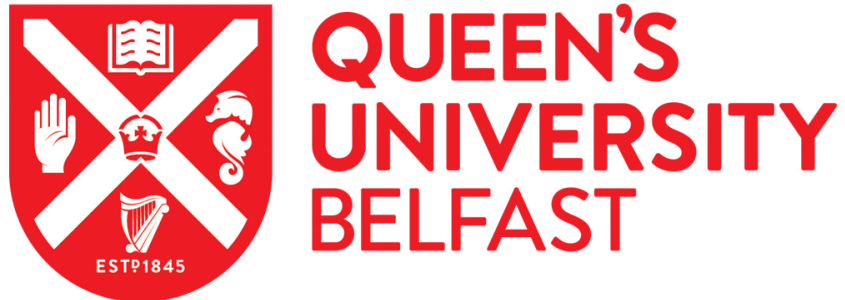

\section{Directional Dependence of Extreme Metocean Conditions for Analysis and Design of Marine Structures}

\author{
Sadat Haghayeghi, Z., Imani, H., \& Karimirad, M. (2020). Directional Dependence of Extreme Metocean \\ Conditions for Analysis and Design of Marine Structures. Applied Ocean Research. \\ https://doi.org/10.1016/j.apor.2020.102181
}

\author{
Published in: \\ Applied Ocean Research
}

\section{Document Version:}

Peer reviewed version

Queen's University Belfast - Research Portal:

Link to publication record in Queen's University Belfast Research Portal

\section{Publisher rights}

Copyright 2020 Elsevier.

This manuscript is distributed under a Creative Commons Attribution-NonCommercial-NoDerivs License

(https://creativecommons.org/licenses/by-nc-nd/4.0/), which permits distribution and reproduction for non-commercial purposes, provided the author and source are cited.

\section{General rights}

Copyright for the publications made accessible via the Queen's University Belfast Research Portal is retained by the author(s) and / or other copyright owners and it is a condition of accessing these publications that users recognise and abide by the legal requirements associated with these rights.

Take down policy

The Research Portal is Queen's institutional repository that provides access to Queen's research output. Every effort has been made to ensure that content in the Research Portal does not infringe any person's rights, or applicable UK laws. If you discover content in the Research Portal that you believe breaches copyright or violates any law, please contact openaccess@qub.ac.uk. 
1 Directional Dependence of Extreme Metocean Conditions for Analysis and Design of

2

3

4

5

6

7

8

9

10

11

12

\title{
Marine Structures
}

\author{
Zohreh Sadat Haghayeghi ${ }^{1}$, Hasan Imani $^{2}$, Madjid Karimirad ${ }^{3}$ \\ ${ }^{1}$ Department of Marine Engineering, Amirkabir University of Technology, Tehran, Iran. \\ Email: z.haghayeghi@aut.ac.ir \\ ${ }^{2}$ Department of Mechanical Engineering, Sharif University of Technology, Tehran, Iran. \\ Email: hasan.imani@mech.sharif.ir \\ ${ }^{3}$ Corresponding author: School of Natural and Built Environment, Queen's University Belfast (QUB), David Keir \\ Building, Stranmillis Road, Belfast, BT9 5AG, Northern Ireland, United Kingdom. \\ Email: madjid.karimirad@qub.ac.uk; Telephone: (+44) 02890974045; Mobile phone: (+44) 07871951856
}




\section{Abstract}

14 Marine structures are typically sensitive to the direction of wind and waves, especially in extreme metocean conditions. The extreme metocean conditions and their associated predicted directions are not easily reachable from traditional design methodologies. In this research, the most probable combinations of different extreme metocean conditions along with their associated direction are predicted for the HyWind Scotland wind farm, Scotland. To achieve this, the Hierarchical Bayesian Modelling approach is applied to define the Joint Probability Distribution Function (JPDF) of four combinations of metocean parameters, including wave direction, wind direction and wind-wave misalignment. The data is provided by the ERAInterim dataset in 40 years (1979-2018). The JPDFs are composed of a marginal PDF of directional variables (a mixture of von-Mises Fischer distributions) and two conditional JPDFs which are defined to satisfy the periodicity and positivity of distribution parameters. Then, applying the Inverse First-Order Reliability Method (IFORM) to the JPDFs, the Environmental Contours (ECs) for four sets of metocean data are developed. The results show that extreme values obtained from ECs, including directional variables, are higher than the values of traditional linear ECs. The maximum 50-year extreme value of wind speed from the JPDF of wind direction, wind speed and wave height is $2 \mathrm{~m} / \mathrm{s}$ higher than the same extreme extracted from the JPDF of wind speed, wave height and period. Another important observed point is that the direction at which the extreme of metocean parameters occurs is quite different from their dominant direction of wind rose or the most probable direction of their probability density function. According to the results, it seems for direction-dependent structures; the application of this method may lead to a more realistic presentation of joint occurrence of linear and directional metocean parameters.

Keywords: Extreme metocean analysis, Joint probability model, Linear and circular statistics, Directional coastlines. 


\section{Introduction}

The development of coastal and offshore structures towards areas with potentially more severe environmental conditions exposes the structures to extreme loading situations. Safety of such structures must, therefore, be ensured under the expected sea states during extreme metocean conditions. This necessitates a reliable estimation of specific important metocean parameters with very low probabilities of occurrence, which might lead to severe damages to the structure. Among all potential marine environmental factors, it is the wind and wave conditions to be considered as influential metocean parameters affecting significantly the design and integrity assessment of many marine engineering applications [1, $\underline{2}]$. Accordingly, current design standards and recommended practices, such as DNV GL's []ㅡ, NORSOK N003 [4], API-RP-2A-WSD [5]], ISO []], IEC 64001-3 standard [7], and ABS []], have issued guidelines prescribing modelling instructions on extreme wind and wave loadings through a series of load cases including either a single load pattern or a combination of load patterns. The required statistical measures of wind and waves in the specified extreme load cases are generally quantified through two types of variables: linear and circular, reflecting magnitude and direction of variables, respectively. The extreme values of linear variables in both single and combined loading patterns are typically assumed to be conditionally independent of their corresponding circular measures (i.e., linear circular-independent variables); and are associated with their frequently occurring values of their circular measures, such as mean or spectral peak directions $[\underline{3-7}, 9]$. However, the probability of experiencing such direction-independent extreme loadings (i.e., single or combined) is very low and has often led to inconsistent estimation of environmental action effects associated with a particular recurrence period in other directions different than the typically considered direction (i.e., mean or spectral peak directions), which could result in inefficient and unreliable designs [10-12], especially in case of directional dependent structures such as non-axisymmetric support structures and mooring systems. This is due to the fact that these parameters are in reality correlated and direction-dependent so that due to the existence of usual multi-hour time lag between wind and wave fields during extreme events, a wind field with most likely less severe magnitude and different direction can be combined with a wave field during its extreme state [13-15].

Several recent studies have addressed this issue and provided some recommendations on probable appropriate treatments, see, e.g., $[\underline{11}, \underline{12}, \underline{16-18]}$. On this basis, to deal with the directional dependence problem, a recommended approach is to apply the directional adjustment factors to the wind and wave extreme values obtained from omnidirectional marginal Probability Density Functions (PDFs) [11, 17, 18]. 
along with this method when time-series of data is not accessible for defining marginal PDFs of each metocean variable [18]. A second approach to obtain directionality consistent extreme values is to develop marginal PDFs within several directional bands, reflecting design requirements and constraints, for wind and wave parameters. In this case, the directional characteristic values must be calculated such that the overall non-exceedance probabilities obtained by the product of survival probabilities in all directions be equal to the desired omnidirectional reliability level [12]. The main problem with these approaches is that the dependence of linear and circular variables is either not taken into account or to some relatively large extent ignored. A third and more realistic approach is to develop a joint probability model of occurrence for metocean variables accounting different combinations of magnitudes and directions [16]. This approach is a multivariate probabilistic method, in which the simultaneous occurrence of extreme values of linear variables dependent on their circular measures could be predicted with an adequate degree of accuracy [ $\underline{3}$, 6, 7]. On this basis, consistent estimation of both single and combined wind and wave actions; and consequently, extreme action effects can then be obtained [16]. The result, in this case, is an envelope also known as "environmental contour", which is, in fact, a simple, economic but yet sophisticated method from computational and accuracy point of views to define an appropriate combination of metocean variables with a specified MRP $[\underline{1}, \underline{2}]$. The quality of environmental contour generally depends on several crucial factors including derivation methodology, probabilistic description of variables, fitting process and goodness-of-fit criteria, joint probability models (JPMs) (i.e., marginality or conditionality of each parameter or in another word structural dependence of variables). In dealing with such difficulties, several computational techniques to establish such multivariate probabilistic description including Inverse First Order Reliability Method (IFORM) [19], Inverse Second-Order Reliability Method (ISORM) [20]), Highest Density Contour (HDC) method [21], and hyper plans-/Monte Carlo-based approaches [22] have been developed. The newly established direct sampling method has been also used for the development of ECs in higher dimensions and directional variables [23, 24]. Moreover, different JPMs [10, 25-27], as well as various parametric [28] and non-parametric [29] statistical approaches have been presented and examined to define marginal/conditional PDF of variables.

\section{The current stage of directional metocean modelling and challenges}

The omni-directional and directional design conditions in combination of individual extreme values have been the subject of many studies (directional adjustment factors and direction-dependent marginal PDFs ) $[\underline{11}, \underline{12}, \underline{16-18}]$. The directionally effects in metocean joint modelling has also been addressed [무, 
101 25-27]. However, the problem of making consistent design criteria using multivariate JPMs considering 102 both intensities and directions of wind and waves is has not been appropriately studied. With this in mind, 103 the main objective of this study is to quantify the influence of direction on the combined extreme values.

104 To accomplish our goal, a series of direction-independent and -dependent multivariate joint metocean 105 models using the Conditional Modelling Approach (CMA) are developed, and the extreme metocean 106 conditions are compared by omnidirectional and directional contours. The joint probability distribution of 107 random variables to capture their inherent interdependence can be estimated by different methods. There is 108 no preferred or recommended method for producing environmental contours from site-specific data sets; 109 however, the differences in the methods mainly result from how dependencies or correlations are defined. Therefore, choosing the best method, which neither under- nor over-estimates the required quantities, is not always straightforward. The CMA can be implemented in the joint probability modelling when the sufficient amount of data in the form of simultaneous multi-variate time series (hindcast or recorded) is available. In the CMA, the first random variable is divided into the bins and a conditional probability function for the second random variable associated with each bin is estimated by analyzing the collected data in each bin. When the environmental data is not present in the form of recorded or hindcast data and just the marginal distribution of data besides their correlations is in hand, an approximate joint probability distribution approach, such as copula [30] and Nataf-based [31] models are used, avoiding the need to search for conditional independence. Nonetheless, the problem with copula and Nataf distribution approaches is that since dependence structure is predefined based on certain correlations, the use of correlation coefficients together with the marginal distribution may not capture the effect of dependence between the variables as it is applicable by described conditional distributions. So, it might not be possible to reflect the underlying shape of the data distribution well. In this case, the shapes of contours are generally rigid concerning the given sample data $[\underline{32}, \underline{33}]$.

This study proposes four different sets of conditional joint models to evaluate the influence of directionality on the extreme metocean condition. The paper is organized as follows: In Section 3, the study area along with utilized metocean data, are presented. In Section 4, the basic methodology for the long-term description of metocean and considered conditional models for metocean linear and circular variables along with multivariate distribution for each representative model is described. The analysis framework and fitting procedure implemented in this study are presented in Section 5. The application of developed joint models in extreme value analysis is discussed in details in Section 6. At last, the discussion on the directional dependency of extreme metocean conditions and remarks are provided in Sections 8 and 9. 


\section{3. Study area and metocean data description}

133 The area considered in the present study is located at the north-western portion of North Sea 134 approximately $25 \mathrm{~km}$ off the northeast coast of Scotland, Peterhead, where a multi-MW floating offshore 135 wind farm known as "Hywind Scotland Pilot Park" over an area of $15 \mathrm{~km}^{2}$ with a water depth around 95$136120 \mathrm{~m}$ is currently operating. An overview of the study area and study point location $\left(57^{\circ} 29^{\prime} 00^{\prime \prime} \mathrm{N}\right.$ and $1371^{\circ} 21^{\prime} 00^{\prime \prime} \mathrm{W}$ ) is presented in Figure 1. To develop the joint distribution of wind and wave parameters, 138 simultaneous wind and wave time histories at the location for a regular time interval of hours over several 139 years (e.g., typically 3-6 hours and 30-50 years, respectively [1]) are needed. In this study, the required 140 long-term data to describe wind and wave environmental conditions are provided by ERA-Interim dataset, 141 a dataset from Numerical Weather Prediction Model (NWPM) of European Center for Medium-range 142 Weather Forecast (ECMWF). [34]. This database is produced by much more accurate atmospheric 143 modelling and assimilation techniques (i.e., better resolution and description of the wind and wave fields) 144 compared to previous ECMWF datasets such as ERA-15 and ERA-40. The accuracies of the ERA-Interim 145 reanalysis wave and wind field data against measurements have also been comprehensively evaluated and 146 verified in various locations, see e.g., [35]. The data contains information regarding wind parameters, 147 including speed and direction along with wave characteristics consisting of wave height, wave period, and 148 direction of the wave. It covers the span of 1979-2018 (40 years) with a temporal resolution of six-hours 149 which means there are about 58440 short-term environmental condition data points in the gathered database. 


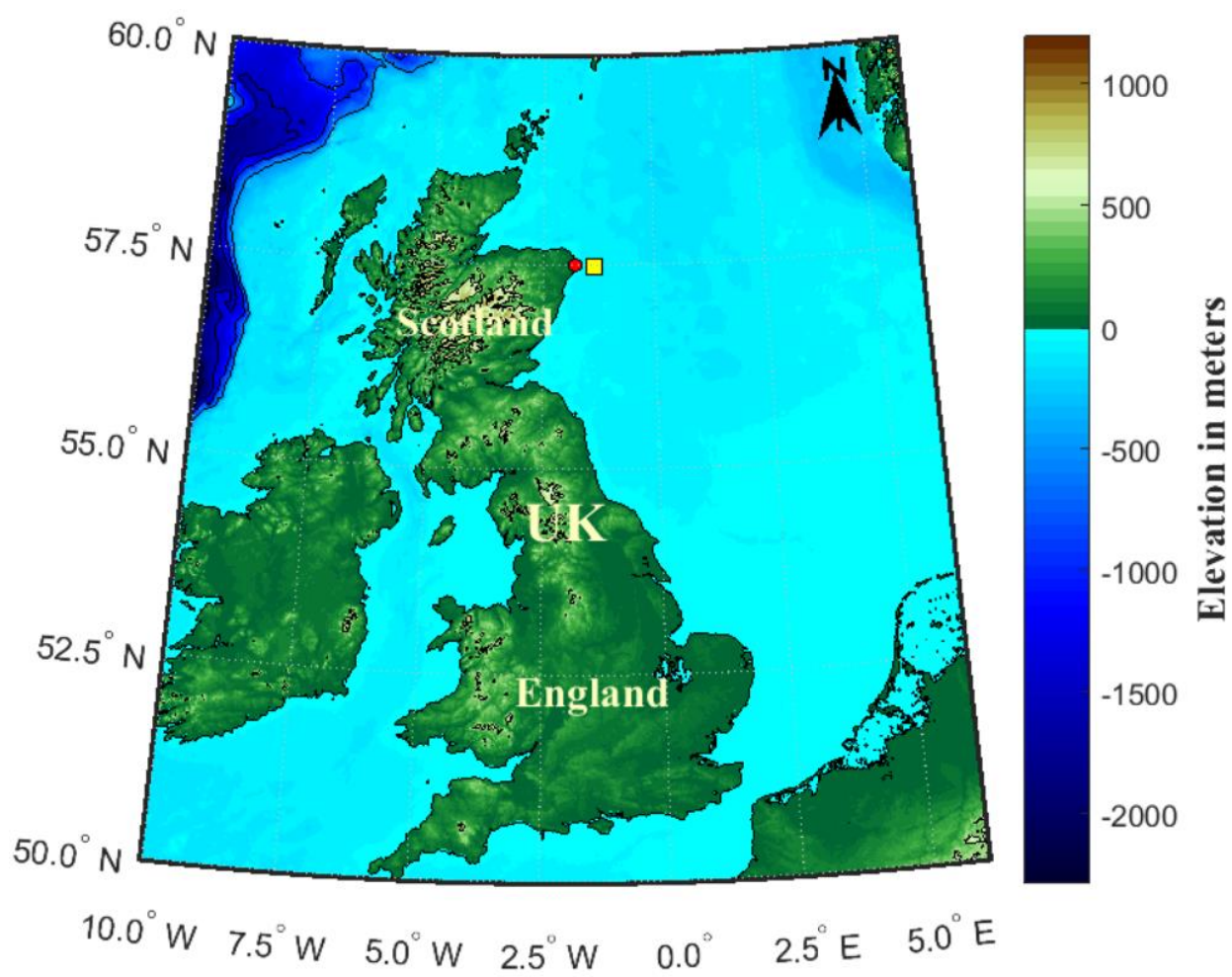

151 Figure 1. Location for study point at Hywind Scotland pilot wind park (yellow point) concerning the coast

152 of Peterhead (red point). (For colour interpretation of this figure, the reader is referred to the web version 153 of this article).

\section{Methodology}

Development of environmental contours (i.e., line in 2D cases and on a surface in 3D cases) is a process composed of generally two main steps: (1) Defining the dependence structure between metocean variables and (2) Establishing the environmental contours either directly in the original variable space (e.g., Monte

159 Carlo-based approaches) or by transforming the variables between physical and standard normal spaces 160 (e.g. IFORM). In the present study, the dependence between variables is described using the Conditional 161 Modelling Approach (CMA) [36], while the joint models of the environmental variables are developed 162 based on inverse first-order reliability method (IFORM) utilizing the Rosenblatt transformation [19,$\underline{37]}$. 163 The theoretical elements of each step are described in details in the following subsections.

\subsection{Dependence modelling of variables}

165 One of the critical issues to obtain practical and reliable environmental contours is to describe the structure of dependence between intensities and associated directions of wind and wave characteristic parameters. To cope with this aspect, recent studies, see, e.g., [10, 25-27], have mainly adopted two 
168 techniques. In the first approach, the directional distributions are conditioned on their most correlated 169 characteristic parameters (i.e., one dependent parameter for conditional variables) as is expected to be 170 compatible with the physics of the phenomenon [26]. For instance, wind direction depends on wind speed, 171 but not vice versa. This model is sophisticated and realistic but can be computationally expensive as it turns 172 out that there is no guaranty to have a unique conditional PDF for each circular variable in all directions. 173 Therefore, alternative simplified but yet sufficiently accurate approaches with up to two dependent 174 parameters for conditional variables have been suggested in order to reduce computational efforts. In these 175 models, as the most widely used ones, the directional distributions are incorporated into at most tri-variate 176 joint probability functions through marginal distributions [1ㅇ, 25, 27]. This is generally a reasonable assumption mainly for the sake of convenience as it is easier to specify one unique PDF to each circular variable or their misalignment in all directions. In this case, the statistical dependencies in generated JPMs have also been defined using IFORM based Nataf transformation approach and CMA [25].

On this premise, the dependence between linear and circular metocean variables in the present study is modelled based on the Conditional Modelling Approach, (CMA). This method assumes that the probability density function of the combination of parameters can be described by the product of marginal distribution of a primary variable and some conditional PDFs of other ones. Therefore, the Joint Probability Distribution Function (JPDF) of random variables $\left(x_{1}, x_{2}, \ldots, x_{n}\right)$ is written as:

$f_{X_{1}, X_{2}, \ldots, X_{n}}\left(x_{1}, x_{2}, \ldots, x_{n}\right)=f_{X_{1}}\left(x_{1}\right) f_{X_{2} \mid X_{1}}\left(x_{2} \mid x_{1}\right) \ldots f_{X_{n} \mid X_{2}, X_{1}, \ldots X_{n-1}}\left(x_{n} \mid x_{1}, x_{2}, \ldots, x_{n-1}\right)$

where $f_{X_{1}}\left(x_{1}\right)$ is the marginal PDF of the primary variable and $f_{X_{n} \mid X_{2}, X_{1}, \ldots X_{n-1}}\left(x_{n} \mid x_{1}, x_{2}, \ldots, x_{n-1}\right)$ is the conditional PDF of the $x_{n}$ given $x_{1}$ to $x_{n-1}$.

Considering the exchangeability of parameters priority in the CMA, one can assume different forms of priority in the Joint probability model. Here, due to the high number of mixture components in the distributions fitted to directional parameters, and to fit less sophisticated forms of interpolation functions, the JPM is set so that the primary variable is the directional one (when one of the variables is directional). On this basis, in the present study, four sets of environmental contours from a combination of six main metocean parameters including both linear and circular variables (i.e., wind speed, $U_{w}$, significant wave

194 height, $H_{s}$, peak wave period, $T_{p}$, wind direction, $\theta_{\text {wind }}$, wave direction, $\theta_{\text {wave }}$, and wind and wave 195 misalignment, $\Delta \theta$ ) have been developed. The JPDF of these sets is first described in Table 1. In all the 196 distributions, it is assumed that the dependence between the second and third variable is negligible as 
197 described by [38]. Each distribution, hereafter termed as D1-D4, is a product of three distributions as

198 defined by Equation 1. These underlying distributions are categorized into two main classes of marginal 199 and conditional distributions. The base distributions of D1-D4 JPMs are a set of marginal distributions, as 200 discussed in Subsection 4.1.1 and three forms of conditional distribution functions as displayed in Table 1. 201 Table 1.

202 The underlying distributions for Environmental Contours developed in this research.

\begin{tabular}{ccccccc}
\hline JPDF & $X_{1}$ & $X_{2}$ & $X_{3}$ & $f_{X_{1}}\left(x_{1}\right)$ & $f_{X_{2} \mid X_{1}}\left(x_{2} \mid x_{1}\right)$ & $f_{X_{3} \mid X_{2}}\left(x_{3} \mid x_{2}\right)$ \\
\hline D1 & $U_{w}$ & $H_{s}$ & $T_{p}$ & Weibull & LLCW & LLCL \\
D2 & $\theta_{\text {wave }}$ & $H_{s}$ & $T_{p}$ & movMF & CLCW & LLCL \\
D3 &.$\theta_{\text {wind }}$ & $U_{w}$ & $H_{s}$ & movMF & CLCW & LLCW \\
D4 & $\Delta \theta$ & $U_{w}$ & $H_{s}$ & movMF & CLCW & LLCW \\
\hline
\end{tabular}

\subsubsection{Marginal PDF of circular variables}

The most naturally observed PDFs for circular parameters are shown to be the wrapped Cauchy, 206 wrapped normal, and circular normal or von-Mises Fischer distribution functions [39, 40]. Among these forms, the von-Mises Fischer distribution function, which reduces to von-Mises distribution in the 2D case and is the normal distribution function projected over the perimeter of the circle, has shown to be the most suitable statistical distribution to model the directionality of metocean parameters, e.g., wind and wave directions [27, 41-43]. This distribution as a symmetric unimodal distribution is defined by its mean value,

$211 \mu \in(0,2 \pi)$, and a concentration parameter, $\kappa>0$, as:

212

$f(\theta)=\frac{1}{2 \pi I_{0}(\kappa)} \exp [\kappa \cos (\theta-\mu)]$

213 where $I_{O}(\kappa)$ is the modified Bessel function of the first kind and zero-order. A mixture of von-Mises Fisher 214 distributions can also be written as:

$f_{\Theta_{w}}(\theta)=\sum_{i=1}^{n} \omega_{i} f_{i}(\theta)$

$0<\omega_{i} \leq 1$,

$\sum_{i=1}^{n} \omega_{i}=1$ 
216 were $\omega_{i}$ are weight coefficients. In the present study, the utilized Expectation-Maximization (EM) 217 algorithm for the log-likelihood of the mixture in the package movMF [44] is applied to find the mixture 218 parameters.

\section{4.1.2. Conditional PDFs of linear and circular variables}

220 The conditional dependence of variables in D1-D4 models is modelled by the three distributions. These 221 distributions appear in different JPMs (i.e., D1-D4) and their parameters are estimated from the underlying 222 data for each distribution.

\section{4.1.2.1. Linear-Linear Conditional Weibull Distribution (LLCW)}

224 The conditional Weibull distribution of variable $x_{i}$ given the linear variable $x_{j}$ is defined by Equation 225

7. The shape and scale parameters of the Weibull distribution fitted to $X_{j}$ are defined as power functions 226 of the primary variable $\left(X_{i}\right)$ :

$f_{X_{i} \mid X_{j}}\left(x_{i} \mid x_{j}\right)=\beta_{l l} \frac{x_{j}^{\beta_{l l}-1}}{\alpha_{l l}^{\beta_{u}}} \exp \left(-\left(\frac{x_{j}}{\alpha_{l l}}\right)^{\beta_{l l}}\right)$

228 where

229

$\alpha_{l l}=c_{1}+c_{2} x_{i}^{c_{3}}$

$\beta_{l l}=c_{4}+c_{5} x_{i}^{c_{6}}$

This model has been applied to demonstrate the dependence between wind speed and wave height in the D1, D3, and D4 models (see also Table 1).

\subsubsection{Linear-linear Conditional Lognormal Distribution (LLCL)}

The conditional lognormal distribution of a linear $x_{i}$ given the linear variable $x_{j}$ can be written as:

$f_{X_{i} \mid X_{j}}\left(x_{i} \mid x_{j}\right)=\frac{1}{\sqrt{2 \pi} \sigma_{\ln X} x_{i}} \exp \left(-\frac{\left(\ln \left(x_{i}\right)-\mu_{\ln X}\right)^{2}}{2 \sigma_{\ln X}^{2}}\right)$

236 in which

$\mu_{\ln X}=d_{1}+d_{2} x_{j}^{d_{3}}$

$\sigma_{\ln X}^{2}=d_{4}+d_{5} \exp \left(-d_{6} x_{j}\right)$

The distribution of wave period given the wave height is assumed to follow this model for D1 and D2 models (see also Table 1). 


\subsubsection{Circular-Linear Conditional Weibull Distribution (CLCW)}

242 The conditional Weibull distribution of a linear variable $x_{i}$, e.g., wave height, dependent on a directional 243 variable, $\theta_{w}$ is defined by:

$$
f_{X_{i} \mid \theta_{j}}\left(x_{i} \mid \theta_{j}\right)=\beta_{c l} \frac{x_{j}^{\beta_{c}-1}}{\alpha_{c l}^{\beta_{d}}} \exp \left(-\left(\frac{x_{j}}{\alpha_{c l}}\right)^{\beta_{c l}}\right)
$$

245 where:

$246 \quad \alpha_{c l}=a_{0}+\sum_{i=1}^{n} a_{n} \cos \left(n \theta_{j}\right)+\mathrm{b}_{n} \sin \left(n \theta_{j}\right)$

247 and

$248 \quad \beta_{c l}=a_{0}+\sum_{i=1}^{n} a_{n} \cos \left(n \theta_{j}\right)+\mathrm{b}_{n} \sin \left(n \theta_{j}\right)$

249 The functions defined by Equation 5 and Equation 6 are Fourier series with non-negative coefficients since 250 the shape and scale parameters of Weibull distribution cannot take negative values, the function should also 251 be periodic in the period of $0^{\circ} \sim 360^{\circ}$ and be able to resemble the shape of data points with reasonable 252 accuracy. This model has been applied to demonstrate the dependence of wind speed and wave height with 253 their corresponding individual directions as well as misalignments in the D2-D4 models (see also Table 1). 254 4.2. Construction of Environmental Surface (ES) for D1-D4

255 A well-known way of tackling problems associated with events of small exceedance probabilities is 256 using the structural reliability methods. If we can assume the performance function of a structural system 257 with $g(X)$, where $X$ is the vector of random variables, the $g(X)=0$ is the failure surface or boundary 258 of the system. The failure probability is defined then by:

$259 p_{f}=\operatorname{Pr}(g(X)<0)=\int_{g(X)<0} f_{X}(X) d X$

260 where $f_{X}(x)$ is the joint PDF of random variables. The integral can be solved by direct numerical integration 261 methods if the $f_{X}(X)$ and $g(X)$ are known functions. The last section described the definition of $f_{X}(X)$ by 262 CMA. The second unknown function is a failure surface $(g(X))$. Most of the structural reliability methods 263 are defined to find a solution for the failure surface at the design point and the IFORM is set so that the 264 failure surface $g(X)$ can be assumed to have a tangent hyperplane in the design point. 
This method transforms the Correlated $X$ variables from the physical space to the uncorrelated 266 Gaussian $U$ variables in the standard normal space. The distance of the design point from the origin in the 267 standard normal space is called the reliability index $\beta$. For the case of standard normal space the reliability 268 index is written as:

$269 \beta=\Phi^{-1}\left(1-p_{f}\right)$

270 where $\Phi$ is the CDF of the standard normal distribution function.

271 The standard normal space which is defined by a hypersphere which can be related to the probability of 272 occurrence of variables and their associated return period as follows:

$273\left\|U^{2}\right\|=\beta^{2}$

274 where $\beta$ is the target reliability level associated with return period $R$ by the following relation:

275

$\beta=\Phi^{-1}\left(1-\frac{T_{s}}{365.25 * 24 * R}\right)$

276 Here $T_{s}$ denotes the duration of each short term observation (here 6-hours) and $R$ is assumed to be in 277 years.

278 Through the definition of variables by CMA, the ECs are defined for each value of $\beta$. The Rosenblatt 279

280 transformation can be written as:

$U_{1}=\Phi^{-1}\left(F_{X_{1}}\left(x_{1}\right)\right)$

$U_{2}=\Phi^{-1}\left(F_{X_{2} \mid X_{1}}\left(x_{2} \mid x_{1}\right)\right)$

$U_{3}=\Phi^{-1}\left(F_{X_{3} \mid X_{2}}\left(x_{3} \mid x_{2}\right)\right)$

281 where $U_{1} \ldots U_{n}$ are the base vectors of the hypercube and defined by:

282

$U_{1}=\beta_{r} \sin \varphi \cos \theta \quad 0 \leq \theta \leq 2 \pi$

$U_{2}=\beta_{r} \sin \varphi \sin \theta \quad 0 \leq \varphi \leq \pi$

$U_{3}=\beta_{r} \cos \varphi$

283 Utilizing this method, any combination of metocean variables can produce their environmental contours 284 when their joint probability distribution function is appropriately described.

\section{Joint models fitting procedure and specifications}

The joint models described in Section 4 has been fitted to the metocean data using MATLAB and the 288 movMF package in CRAN-R [44]. To this aim, first, the marginal PDF of the primary variable is estimated 
289 and then according to the order of variables in each model, the data has been sorted in bins, and the functions 290 have been fitted to each related conditioned parameter. For example, the D1 JPM as described in Table 1 is 291 a product of marginal PDF of wind speed $\left(f_{U_{w}}\left(u_{w}\right)\right)$ as will be mentioned in Table 2 and two conditional 292 JPDFs. The first one is the LLCW of wave height given wind speed $\left(f_{H_{s} \mid U_{w}}\left(h_{s} \mid u_{w}\right)\right)$ and the second one is 293 the LLCL of wave period given the wave height $f_{T_{p} \mid H_{s}}\left(t_{p} \mid h_{s}\right)$. Accordingly, for the $f_{H_{s} \mid U_{w}}\left(h_{s} \mid u_{w}\right)$, the 294 values of wave height $H_{s}$ are sorted and binned according to their corresponding values of wind speed $U_{w}$ 295 , and then the conditional Weibull distribution of Equation 4 is fitted to the sorted and binned data by 296 nonlinear-least squares method to define the parameters of Equations 5 and 6. For the $f_{T_{p} \mid H_{s}}\left(t_{p} \mid h_{s}\right)$ after 297 binning and sorting the data, the LLCL of Equation 7 with parameters defined in Equations 8 and 9 is fitted 298 in the same way. After defining the parameters of all the distributions, the ECs are produced applying the 299 methodology described in Section 4.2. The overall process of the methodology applied in this research to 300 conclude the directional interference of metocean parameters is illustrated in Figure 2. 


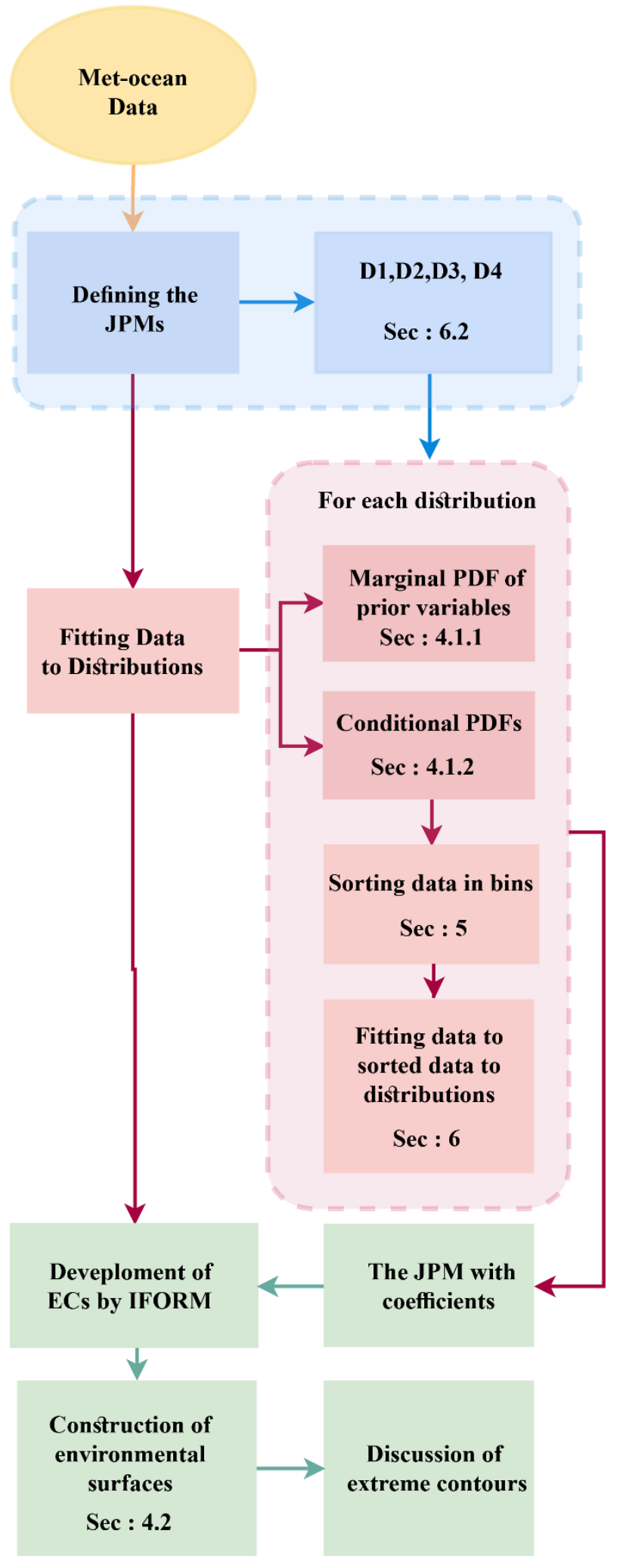

302 Figure 2. A detailed flowchart of the analysis framework steps. 


\section{Results}

In this section, two methods used to calculate the extreme values of linear and circular variables with a particular recurrence period are described. The first method commonly utilized in practice is a univariate distribution modelling of the data, in which the dependency of variables is ignored, and a second method proposed in this paper consisting a series of multivariate/joint distribution of linear and circular variables.

\subsection{Raw data marginal distributions and correlation}

In this section, the extreme values of linear variables from their marginal distributions are calculated from the marginal distributions fitted to them. To this aim, the marginal distributions of linear metocean variables (i.e., significant wave height $\left(H_{s}\right)$, mean wind speed $\left(U_{w}\right)$, mean wave period $\left.\left(T_{p}\right)\right)$ are displayed in Figure 2, while the probability density function of directional variables (i.e., mean wave and wind directions $\left(\theta_{\text {wave }}\right.$ and $\left.\theta_{\text {wind }}\right)$ as well as wind and wave misalignment $(\Delta \theta)$ are shown in Figure 3. Table 1 also lists the variables and the distributions fitted in Figure 2 and Figure 3d-f. Moreover, the number of components estimated for each circular variable is presented in

Table 2. The details of the components are listed in Table A1 of the Appendix. The rose diagram for wind direction, wave direction, and wind-wave misalignment are plotted in Figure 3a-c. The correlation coefficients between the parameters as an informative measure of the concurrency of variables were also calculated using the Spearman's Rho [45] formulation and listed in

Table 3. These correlations between circular and linear variables (1-c), (1-l) for linear and (c-c) for circular variables will be discussed later. The Spearman's Rho is a measure of association which evaluates the monotonicity in the values of two variables, i.e. their tendency to change together in the same way, but not necessarily with a constant rate. If two variables are in a robust relationship but their relation is not monotonic, the Spearman's Rho may be significantly low. As it is expected, (1-1) coefficients showing a correlation between $\left(H_{s}, U_{w}\right)$ and then $\left(H_{s}, T_{p}\right)$ hold the highest values in

Table 3. The dependency between $\left(U_{w}, T_{p}\right)$ is considerably low in contrast to the other (1-1) correlations, which was the base for the assumption of dependency between $\left(U_{w}, T_{p}\right)$ in the D1 distribution. The definition of (l-c) and (c-c) correlation coefficients, based on the Spearman's Rho, are different than (1-l) and thus quite different values should be expected. When it comes to calculation of this measure for circular and linear variables, the concept becomes more complicated; i.e. the tendency of variables to decrease or 
332 decrease in the same way for the circular and linear variables is not physically easy to interpret. While in 333 the case of (1-1) and (c-c) the concurrency of variables can be observed and understood more easily.

334

335

336

337

338

339

340

341

342

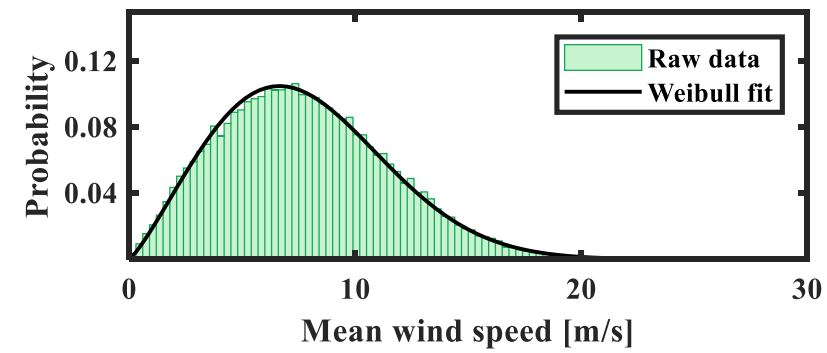

(a)

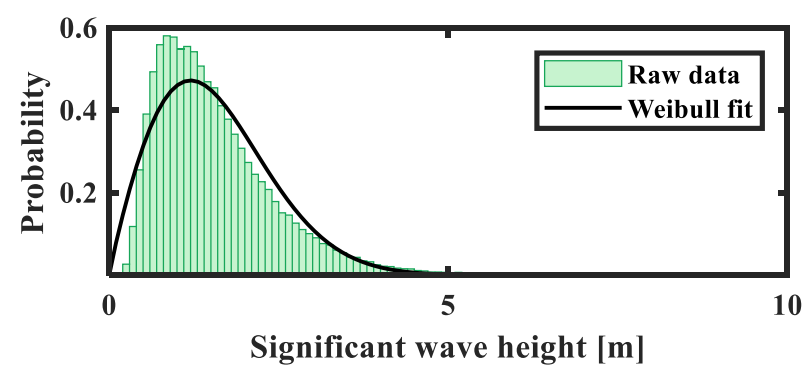

(b)

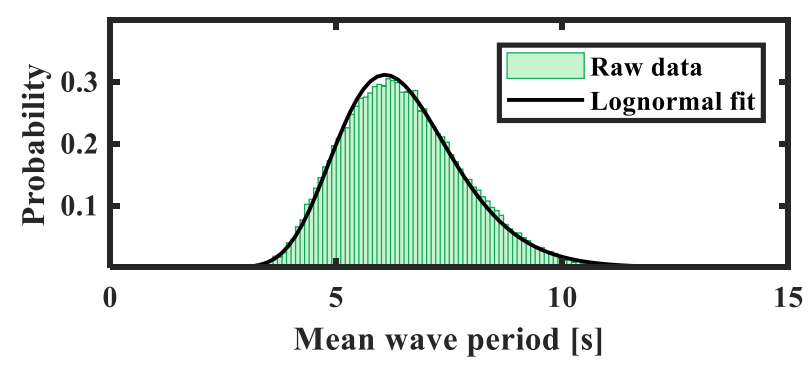

(c)

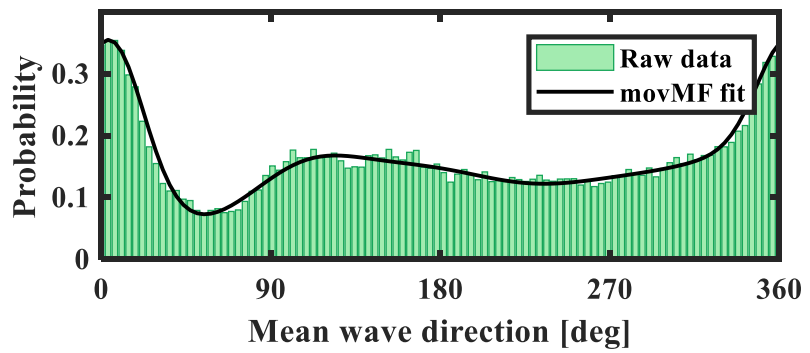

(d)

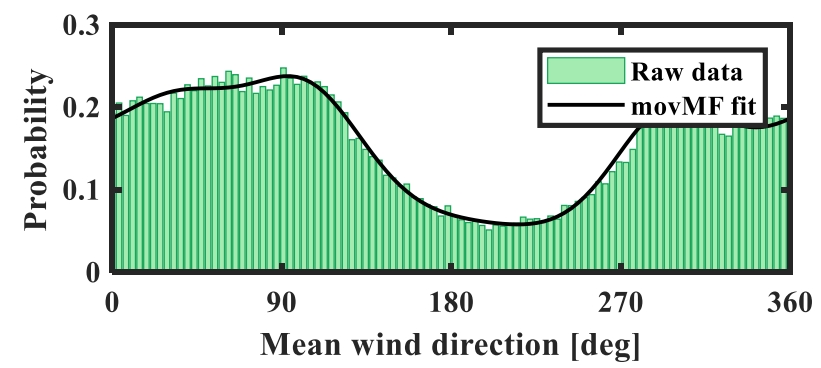

(e)

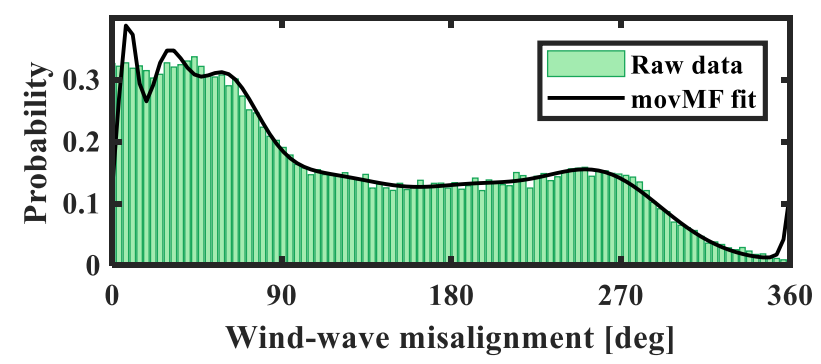

(f)

Figure 3. Marginal distribution of linear (left panel) and directional (right panel) variables for the metocean data (from 1979 to 2018): (a) Mean wind speed, (b) Significant wave height, (c) Mean wave period, (d) Mean wave direction, (e) Mean wind direction, (f) wind-wave misalignment.

As shown in

Table 3., the (1-c) correlation coefficient of $\left(H_{s}, \theta_{\text {wind }}\right)$ is higher than that of $\left(H_{s}, \theta_{\text {wave }}\right)$. Here a question may arise that why the wave height is more dependent on the wind direction than on the wave direction.

Referring to the origin of Spearmen's Rho, which is how the $H_{s}$ and $\theta_{\text {wave }}$ can affect interchangeably, may help to answer the question. Since the waves are known to be mainly wind-generated, it is acceptable that the waves are affected by the wind direction and also because the wave direction is dependent on the 
349 topology of the site and the changes in the wave direction toward the shoreline and changes in the depth.

350 The correlation between $\left(U_{w}, \Delta \theta\right)$ and that of $\left(H_{s}, \Delta \theta\right)$, on the other hand, are close to each other, while 351 the misalignment has a bit more tendency to be affected by $U_{w}$. The (c-c) correlation between $\left(\theta_{\text {wave }}, \Delta \theta\right)$

352 is the only negative value in Table 3 . While the (c-c) correlation coefficient of $\left(\theta_{\text {wind }}, \Delta \theta\right)$ takes the 353 reasonably high value of 0.161 . This means the increase in the misalignment is much more dependent on 354 the wind direction, while it is inversely dependent on the wave direction. Another issue about the slightly 355 low values of (c-c) and (l-c) correlation coefficients can be explained by the fact that although winds 356 generate waves, there are usually time lags between highest values of winds and waves. Therefore, the 357 extreme values of wind speeds and wave heights do not coincide, and this leads to lower values of 358 correlation coefficients.

\section{Table 2.}

360 Metocean variables used in this research and their marginal distributions.

\begin{tabular}{ll}
\hline Variable & Distribution \\
\hline Mean wind speed $\left(U_{w}\right)$ & Weibull $(\alpha=8.742 \quad \beta=2.206)$ \\
Significant wave height $\left(H_{s}\right)$ & Weibull $(\alpha=1.766 \quad \beta=1.916)$ \\
Peak wave period $\left(T_{p}\right)$ & Log-normal $(\mu=1.847 \quad \sigma=0.206)$ \\
Mean wind direction $\left(\theta_{\text {wind }}\right)$ & A mixture of von-Mises $(\mathrm{n}=8)$ \\
Mean wave direction $\left(\theta_{\text {wave }}\right)$ & A mixture of von-Mises $(\mathrm{n}=6)$ \\
The absolute value of $\theta_{\text {wave }}-\theta_{\text {wind }},(\Delta \theta)$ & A Mixture of von-Mises $(\mathrm{n}=12)$ \\
\hline
\end{tabular}

\section{Table 3.}

363 The Spearman's Rho correlation coefficient between variables.

\begin{tabular}{ccccccc}
\hline & $U_{w}$ & $H_{s}$ & $T_{p}$ & $\theta_{\text {wind }}$ & $\theta_{\text {wave }}$ & $\Delta \theta$ \\
\hline$U_{w}$ & 1 & 0.773 & 0.149 & 0.141 & 0.348 & 0.101 \\
$H_{s}$ & & 1 & 0.644 & 0.108 & 0.069 & 0.094 \\
$T_{p}$ & & & 1 & 0.185 & 0.346 & 0.149 \\
$\theta_{\text {wind }}$ & & & & 1 & 0.369 & 0.161 \\
$\theta_{\text {wave }}$ & & & & & 1 & -0.131 \\
$\Delta \theta$ & & & & & & 1 \\
\hline
\end{tabular}




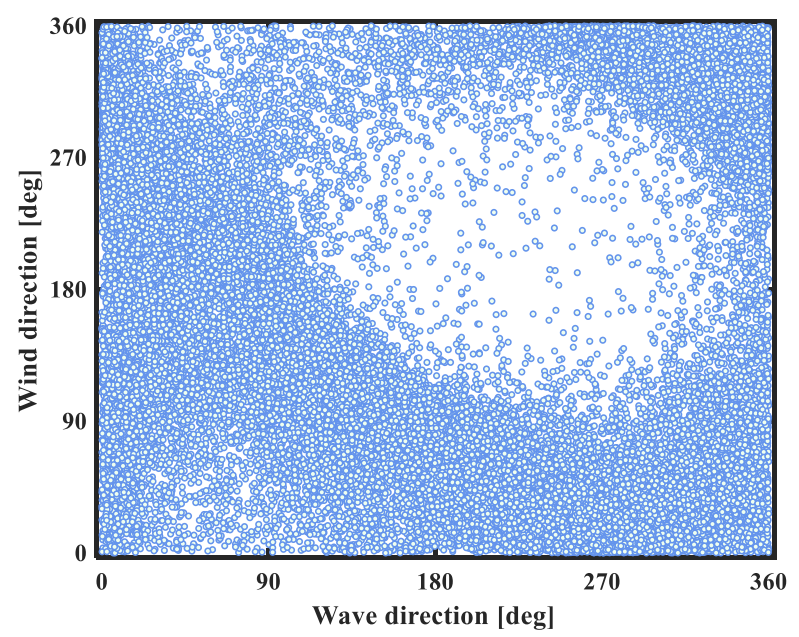

366 Figure 4. Scatter plot of wind direction vs. wave direction.

367 Figure 4 is the scatter plot of wave and wind directions. The area between $120^{\circ} \sim 300^{\circ}$ is lighter in 368 density and less scattered which is in accordance with the density plots as shown in Figure $3 \mathrm{~d}$ and Figure $3693 \mathrm{3}$. The rose diagram for wind speed and direction, wave height and direction and wind-wave misalignment 370 and wind speed are plotted in Figure 5a-c. The rose plot of wind and wave misalignment in Figure $5 \mathrm{c}$ shows 371 372 the gradual decrease in the density of wind speeds with the increase of misalignment from $0^{\circ}$ to $360^{\circ}$. It can 373 also be seen that the misalignment between wave and wind direction is less than $90^{\circ}$ in a majority of wind and wave combinations. It is to be noted that the wind-wave misalignment is defined as the absolute value 374 of the difference between wind and wave directions, as mentioned in Table 1.

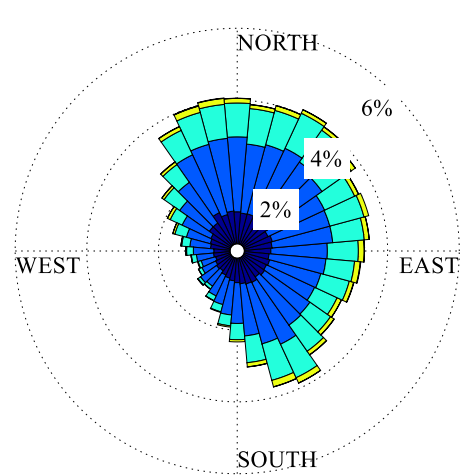

(a)

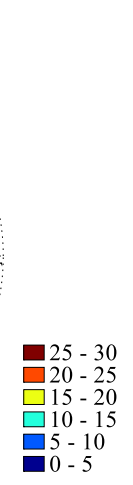

377

378

379 380 $(\mathrm{m} / \mathrm{s})$.

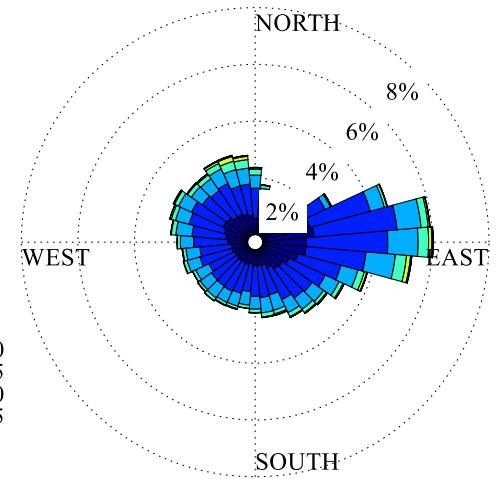

(b)

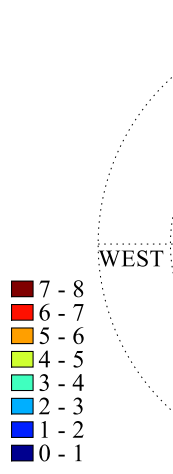

sout

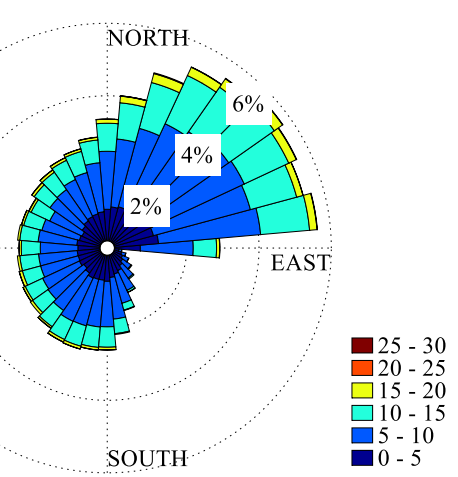

(c)

Figure 5. Density of directional parameters in different directions (a) Wind direction vs.wind speed $(\mathrm{m} / \mathrm{s})$ (b) Wave direction vs.wave height $(\mathrm{m})(\mathrm{c})$ Absolute value of wind-wave misalignment vs. wind direction 


\subsection{Multivariate extreme metocean conditions calculation}

382 The environmental contours for distributions D1 to D4 models have been developed using the above383 described methodology. The results for a mean return period of 50 years are presented in Figure 6 to Figure 3849 , respectively. Each figure is composed of four parts (a-d), where the overall view of the surface is 385 displayed in part (a) and the contours of surface elevation in three planes are shown in parts (b) to (d). 6.2.1. D1 model

387 The developed EC for D1 model (i.e., $U_{w}, H_{s}$ and $T_{p}$ ) is displayed in Figure 6. In this case, the related 388 parameters of wind speed marginal distribution as the primary variable are reported in

Table $\mathbf{2}$, and the parameters of the conditional distribution of wave height and wave period are listed in 390 Table A4 and Table A5. According to Figure 6a., the entire environment surface is expanded in $T_{p} \sim(2.5$ s-12.2 s), $H_{s} \sim(0-7.4 \mathrm{~m})$, and $U_{w} \sim(0-26 \mathrm{~m} / \mathrm{s})$, such that the contours of $U_{w}$ shrink to smaller areas and get concentrated on more specified values of $H_{s}$ and $T_{p}$ as $U_{w}$ increases. It can also be seen that the contour 393 line corresponding to $U_{w}=26 \mathrm{~m} / \mathrm{s}$ is located where $H_{s}$ and $T_{p}$ experience fewer values than the 394 corresponding values at the contour line associated with $U_{w}=25 \mathrm{~m} / \mathrm{s}$ meaning that the maxima of $T_{p}, H_{s}$ 395 and $U_{w}$ are not located at the same representative point. This is more evident in Figure 6(b-d) where the 396 values of $H_{s}$ and $T_{p}$ for the highest range of $U_{w}$ between $6.17 \mathrm{~m}$ and $6.94 \mathrm{~m}$ and $10.27 \mathrm{~s}$ and $11 \mathrm{~s}$, 397 respectively, while the extreme value of wave height and wave period (i.e., $7.35 \mathrm{~m}, 12.2 \mathrm{~s}$ respectively) 398 occur in lower values of wind speed, (i.e., $24.74 \mathrm{~m} / \mathrm{s}, 8.5 \mathrm{~m} / \mathrm{s}$ respectively). 
399

400

401

402

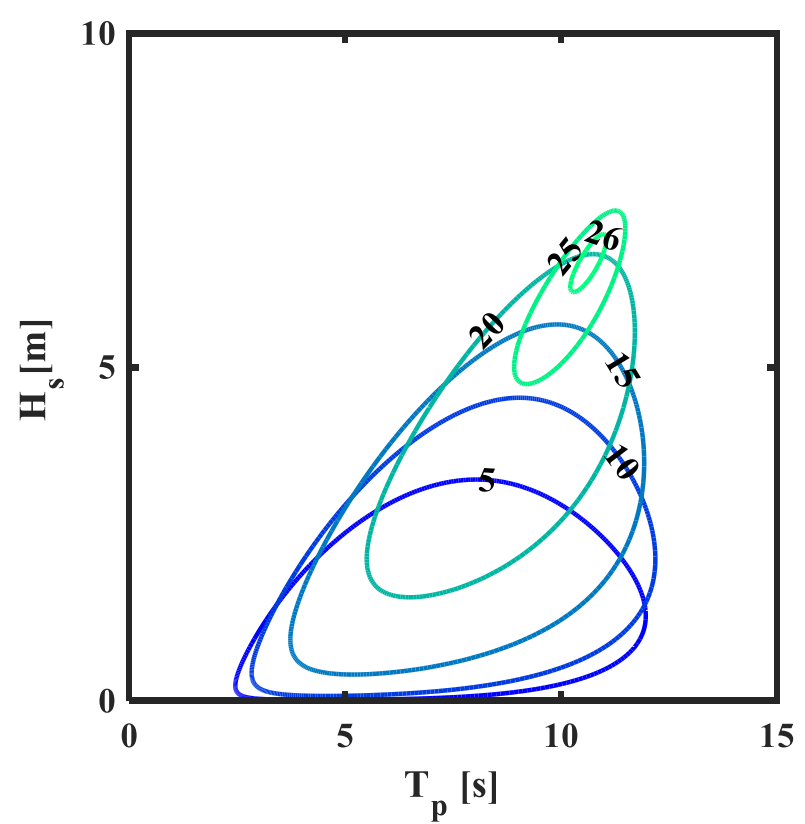

(b)

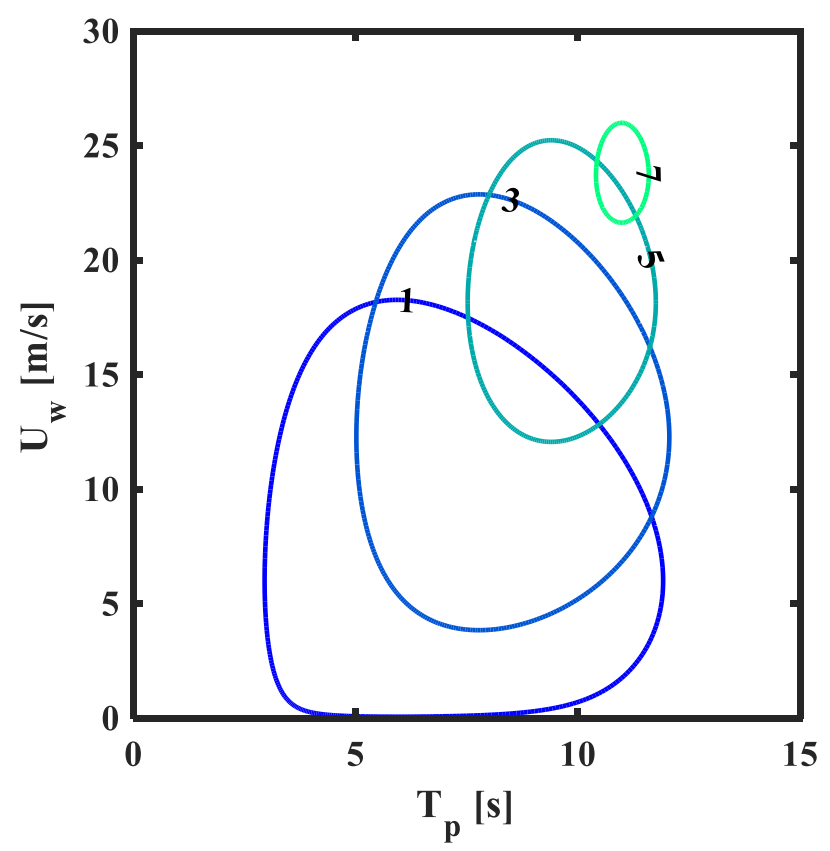

(d)

403 Figure 6. ES (environmental surface) envelope developed for D1 distribution: a) The overall view of the 404 surface, b) contour lines of $U_{w}$ in $\left.(\mathrm{m} / \mathrm{s}), \mathrm{c}\right)$ contour lines of $T_{p}$ in $(\mathrm{s})$, and d) contour lines of $H_{s}$ in $(\mathrm{m})$. 


\subsubsection{D2 model}

The ES (environmental surface) developed based on D2 model for wave parameters, including significant wave height $\left(H_{s}\right)$, mean wind direction, and $\left(\theta_{\text {wave }}\right)$ mean wave period $\left(T_{p}\right)$ is shown in Figure 7. The parameters of the model for wave direction as the primary variable are reported in Table A1. This ES (environmental surface) is an extension of the LonoWe model (which is a JPDF of wave height and period) for all the wave directions. Table A6 and Table A4 also report the related parameters of wave height and wave period distributions, respectively.

Figure 7a displays the surface and the underlying data, and it shows that there are multiple peaks in the $H_{s}-T_{p}$ values in specific wave directions showing irregular and non-monotonic behaviour. Figure $7 \mathrm{~b}$ shows the contours of $H_{s}-T_{p}$ for different wave directions. As the contours take more extreme sea states, they tend to get deformed and have a sharp edge on the most extreme point. The least value of $T_{p}$ in the contours is more than $2.3 \mathrm{~s}$ which complies with the underlying distribution of $T_{p}$ as shown in Figure $3 \mathrm{c}$ that shows the minimum value of $T_{p}$ at the $2.2 \mathrm{~s}$. The highest value of $T_{p}$ in almost all the contours is $12.2 \mathrm{~s}$. The most extreme contour exists at the $106^{\circ}$ where $H_{s}=8.4 \mathrm{~m}$ and $T_{p}=12.2 \mathrm{~s}$. The other peaks in the surface also appear close to the $0^{\circ}$. This also supports what can be inferred from Figure $3 \mathrm{~d}$, where the density of directions near $0^{\circ}$ is higher than in the other regions. If the design approach suggests selecting the design direction based on the density plot of wave directions, the $0^{\circ}$ can be the right choice according to Figure $3 \mathrm{~d}$. However, the present method reveals that the most extreme sea states occur in the $106^{\circ}$, while this direction does not take a high-density value in the density plot (Figure 3b). This kind of understanding cannot be comprehended just from the rose plot of wave direction (Figure 4a) or the density plot (Figure 3b). Figure $7 \mathrm{c}$ also demonstrates the regions of high $H_{s}$ values with contours of $H_{s}=7 \mathrm{~m}$ and $8 \mathrm{~m}$ around $106^{\circ}$. Figure $7 \mathrm{~d}$ demonstrates the levels of $T_{p}$ for different values of $H_{s}$ and $\theta_{\text {wave }}$. The contour of $T_{p}=12 \mathrm{~s}$ also shows a peak around the most severe direction $\left(\theta_{\text {wave }}=106^{\circ}\right)$. 


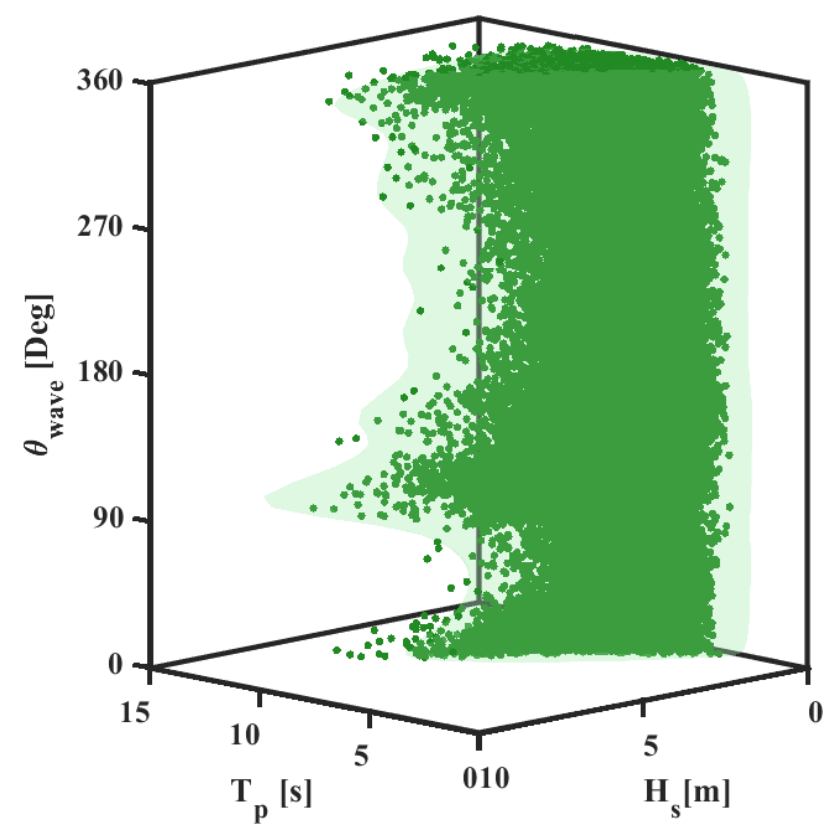

(a)

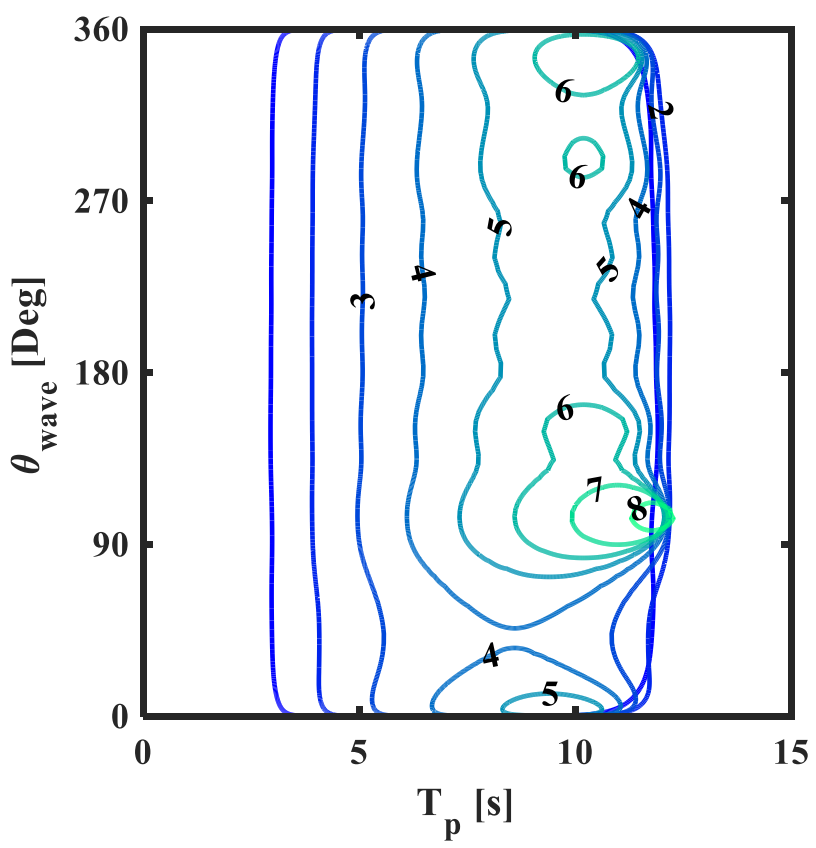

(c)

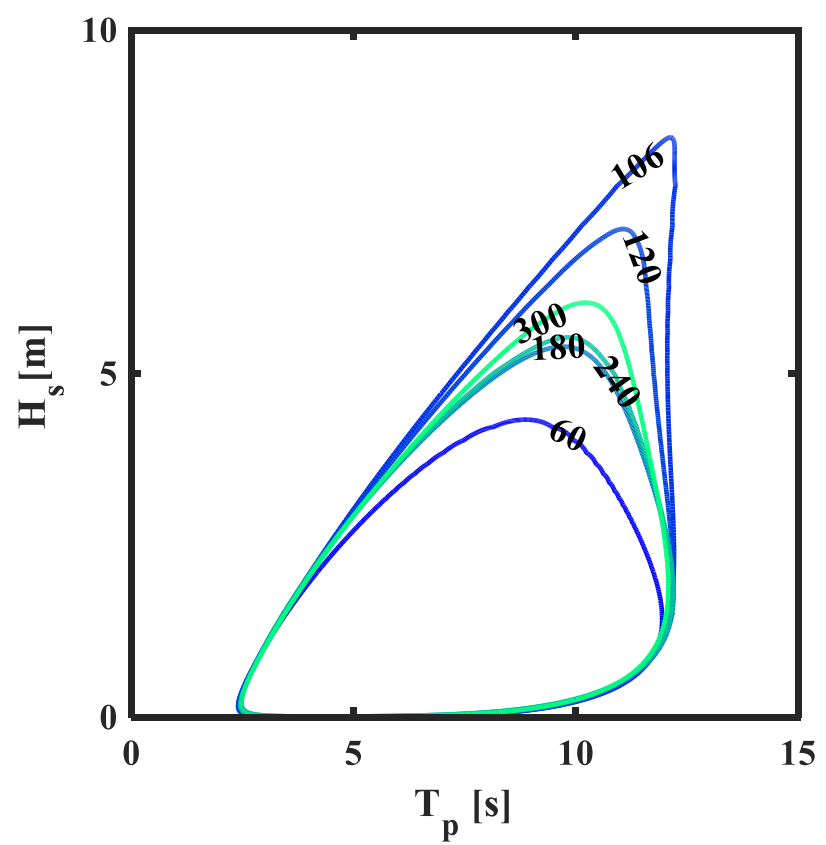

(b)

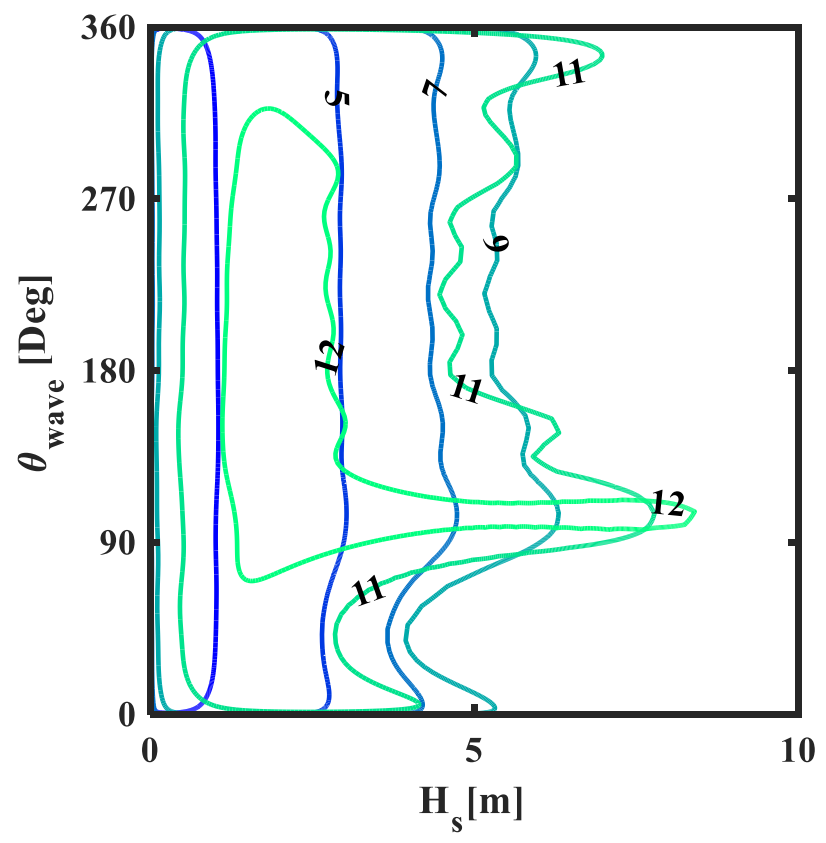

(d)

432 Figure 7. ES developed for D2 distribution: a) The overall view of surface b) Contour lines of $\theta_{\text {wave }}$ in 433 (Degrees), c) Contour lines of $H_{s}$ in (m), and d) Contour lines of $T_{p}$ in (s) 
.

(5)

60

\subsubsection{D3 model}

The ES developed based on D3 model for the combination of wind direction, speed, and wave height is presented in Figure 8. The related distribution parameters of wind direction, wind speed, and wave height are tabulated in Table A2, Table A7, and Table A5, respectively. Figure 8a shows the surface with the peaks on both sides of $0^{\circ}$ (i.e., $5^{\circ}$ and $354^{\circ}$ ) and in the $159^{\circ}$. In the direction of $159^{\circ}$ the surface shows the extreme sea state of $H_{s}=8.19 \mathrm{~m}$ and $U_{w}=28.28 \mathrm{~m} / \mathrm{s}$. Figure $8 \mathrm{~b}$ shows the contours of $\theta_{\text {wind }}$ in the $U_{w}-H_{s}$ plane. A pronounced feature of these contours is their tendency to have a virtual tangent line in their right side, none of the contours crosses this line. The line can be physically related to the wave heights which are possible to be developed in the associated wind speed. For example, in the $U_{w}=15 \mathrm{~m} / \mathrm{s}$, the $H_{s}$ in none of the contours exceeds the value of $5.6 \mathrm{~m}$. The interpretation of the reason for such a phenomenon needs a more precise analysis of the physical interaction of wind and waves. The wave data used in this research is the significant height of combined wind waves and swell as provided by ECMWF in the ERA-Interim database and there is no information available on the percentage of each component. So it can not be concluded directly from the shape of contours that the wave heights are related to the wind speeds (due to the existence of swells). But since the contours are generated from the JPMs derived from the raw data without applying any other filter. To explain this phenomenon, as an observed feature the physical interaction between wind speeds, fetch length, duration of blowing, water depth and bathymetry shape should be investigated which is out of the scope of this research. The contours of $U_{w}-H_{s}$ are plotted in Figure 8c in which the region around the $159^{\circ}$ direction is highlighted with contours of increasing values of he Tform 25 to $28 \mathrm{~m} / \mathrm{s}$. $U_{w}$ same region is also observable with high values of $H_{s}$ in Figure 8d where the contours of $U_{w}$ in the $H_{s}$ $\theta_{\text {wind }}$ plane are plotted.

\section{7}


462

463

464

465

466

467

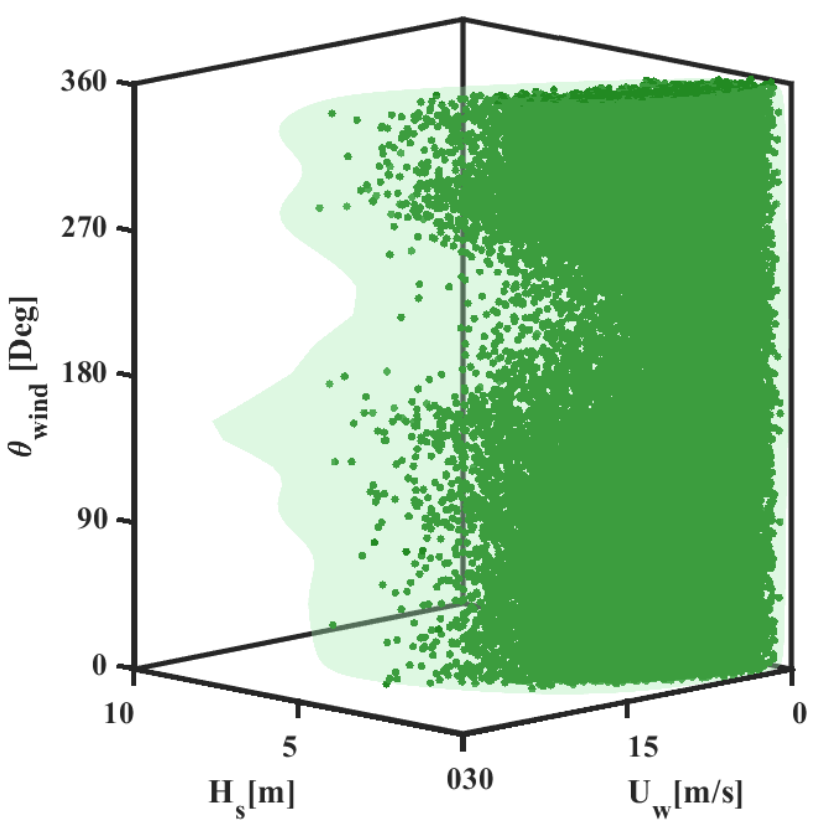

(a)

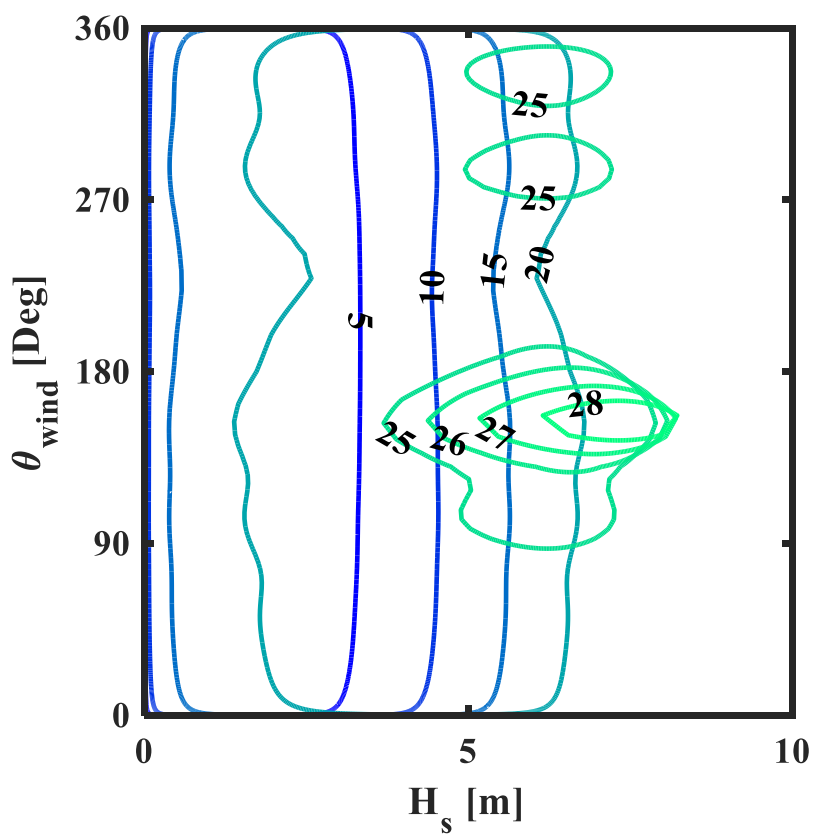

(c)

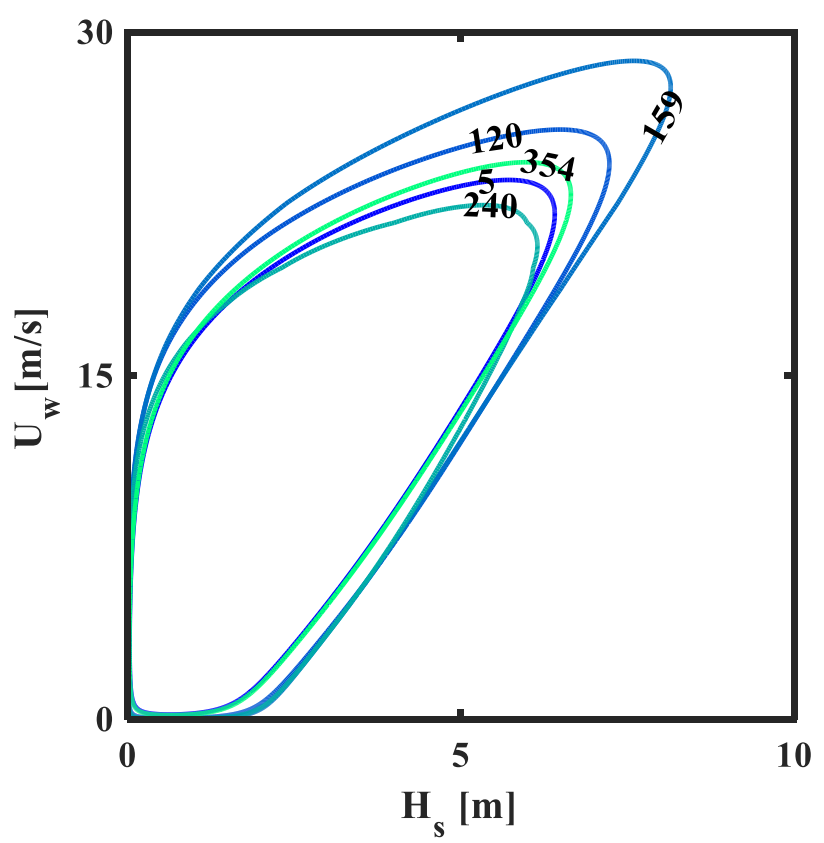

(b)

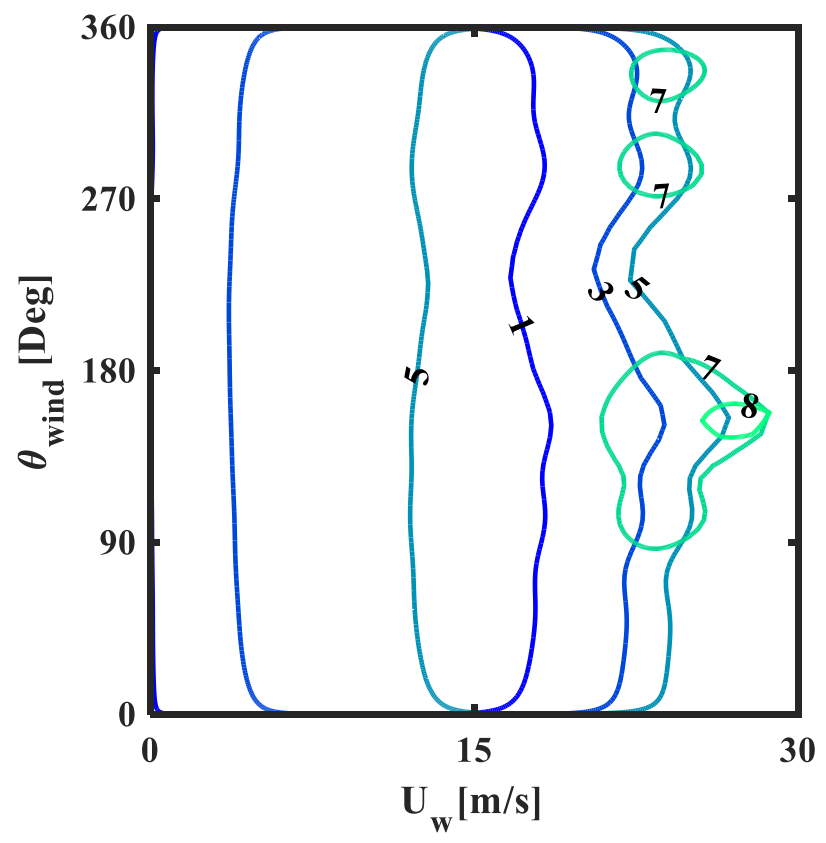

(d)

Figure 8. ES developed for D3 distribution: a) The overall view of the surface, b) Contour lines of $\theta_{\text {wind }}$ in (Degrees), c) Contour lines of $U_{w}$ in $(\mathrm{m} / \mathrm{s})$, and d) Contour lines of $H_{s}$ in (m). 


\subsubsection{D4 model}

The ES for the wind-wave misalignment, wind speed, and wave height, developed based on the D4 model is shown in Figure 9. The related distribution parameters for misalignment, wind speed, and wave height can be found in Table A3, Table A8, and Table A5, respectively. It can be seen from Figure 9a that the value of misalignment increases as its probability of occurrence decreases, which complies with Figure 3f. This means wind and waves frequently happen from close directions. The contour lines of $H_{s}$ and $U_{w}$ shown in Figure 9(b-d) also show that the most extreme combination of $\Delta \theta, U_{w}$ and $H_{s}$ occurs in the $68^{\circ}$ where $U_{w}$ and $H_{s}$ are $27.41 \mathrm{~m} / \mathrm{s}$ and $7.1 \mathrm{~m}$, respectively. Additionally, it is seen that high values of $H_{s}$ and $U_{w}$ are also likely to occur in $142^{\circ}$ and $191^{\circ}$ misalignments. Moreover, from Figure 9c and Figure 9d, it can be seen that the contour lines corresponding to the highest values of $H_{s}$ and $U_{w}$ are mostly located in the misalignment values less than $180^{\circ}$ signifying lower probability of occurrences of opposite directions for wind and waves in the severe sea states. 


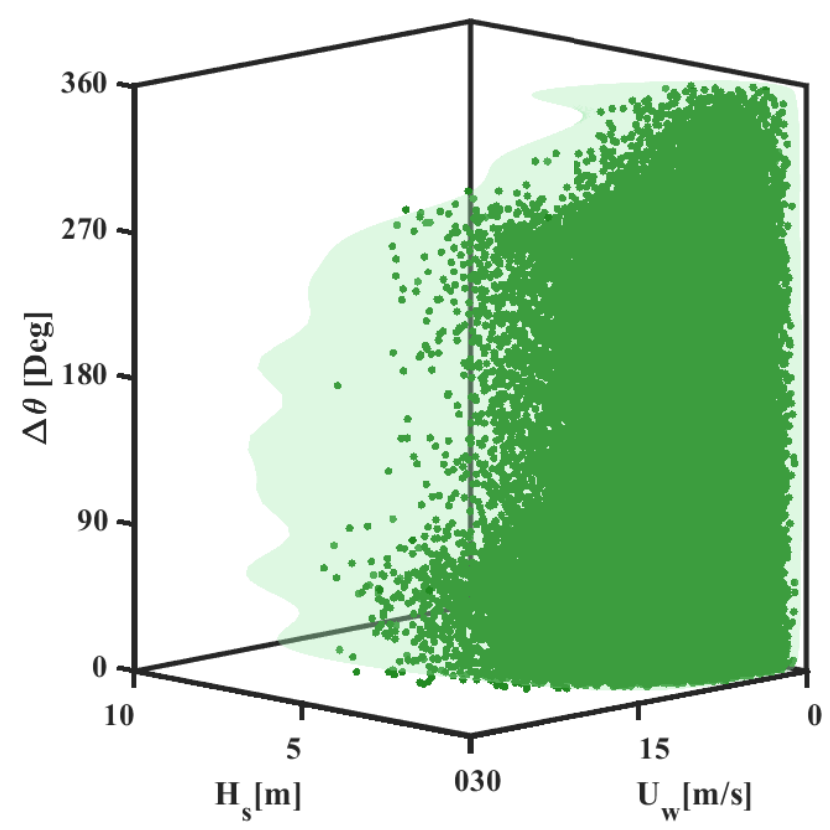

(a)

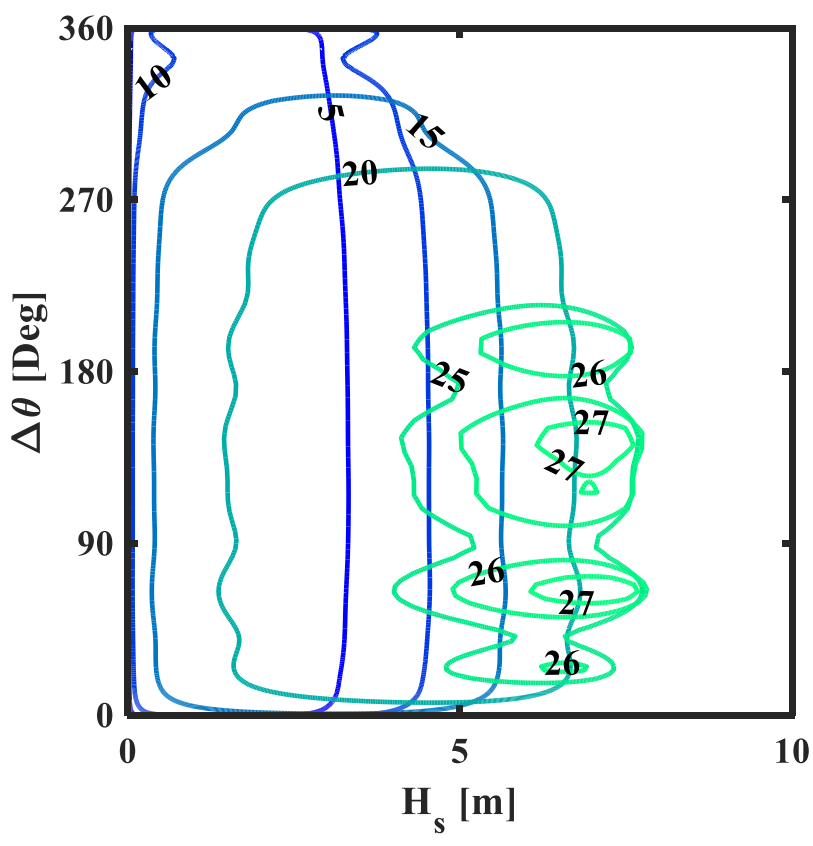

(c)

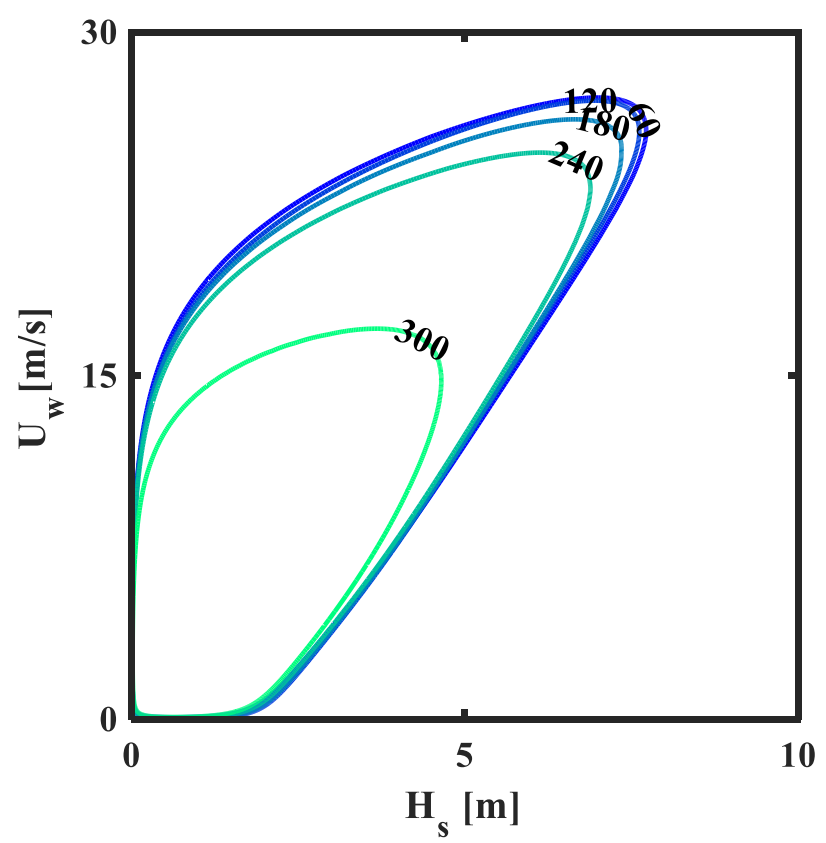

(b)

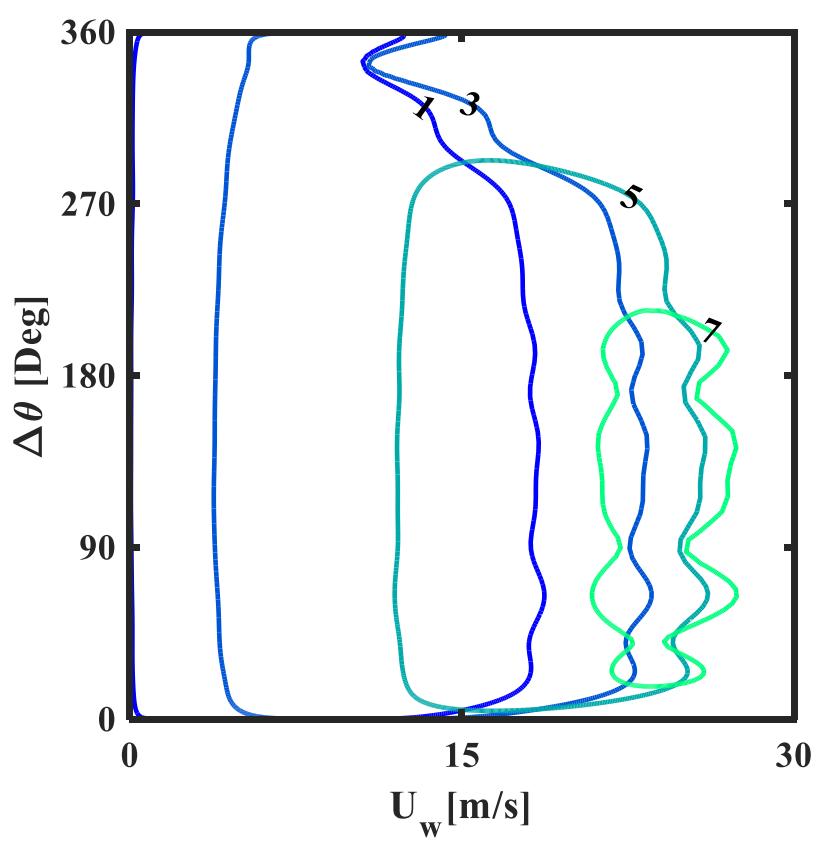

(d)

Figure 9. The ES developed for D4 distribution: a) The overall view of the surface, b) contours of $\Delta \theta$ in 491 (Degrees), c) contours of $U_{w}$ in $\left.(\mathrm{m} / \mathrm{s}) \mathrm{d}\right)$ contours of $H_{s}$ in $(\mathrm{m})$. 
494

495

496

497

498

499

500

501 502

\section{Model diagnostics and validation}

The purpose of applying the probability models in this research is to describe the dependence of variables and generate samples similar to underlying data. The accuracy of the fits of the proposed model was investigated by nonlinear regression. Afterwards, a series of samples were generated by Monte Carlo (MC) method and the RMSE (Root mean square Error) of the model was studied through comparison of the underlying hindcast data and generated samples. The methodology of developing the JPDFs and the ECs was described in Sections 4 and 5. To test the models, the R-squared values of the fits were observed calculated. As an example, the fits of the LLCL and CLCW distributions fitted to raw data for the D2 model besides their R-squared values are reported in Figure 10.

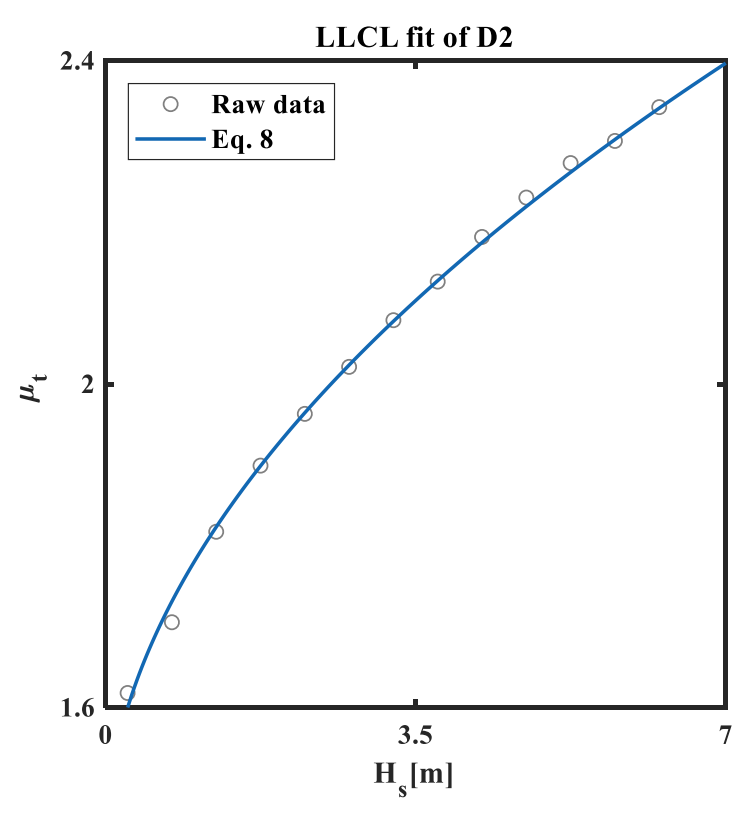

(a)

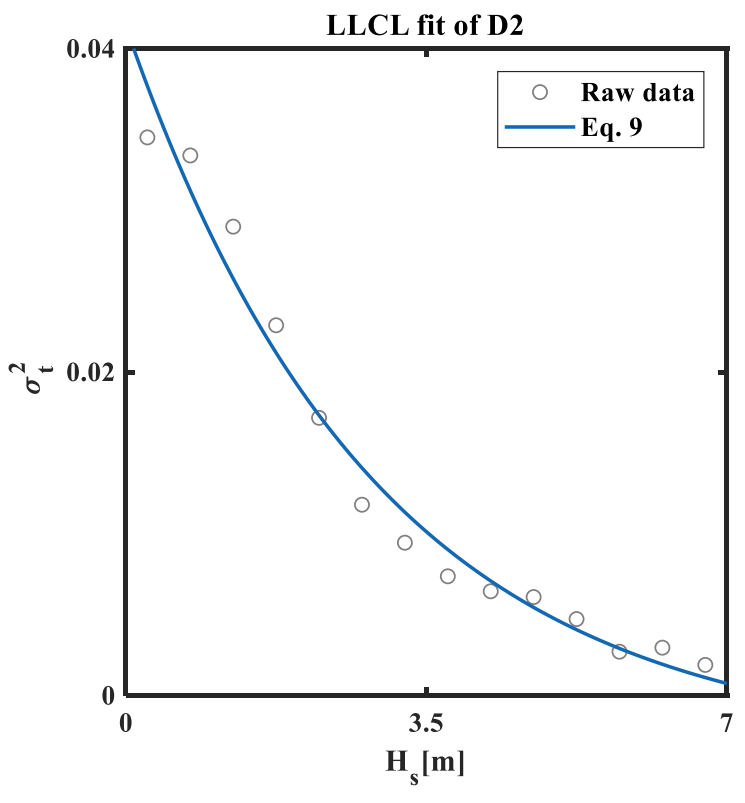

(b) 


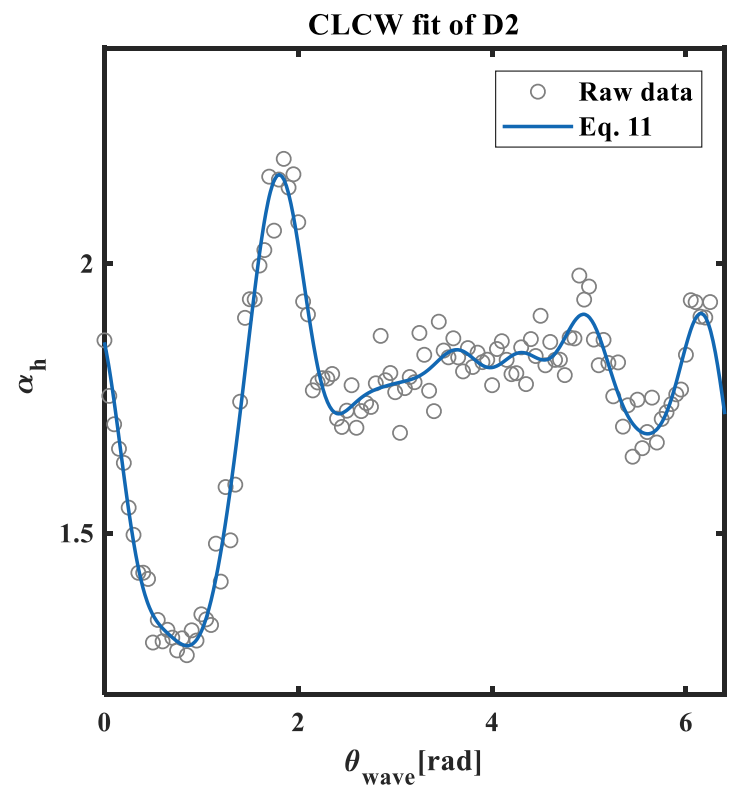

(c)

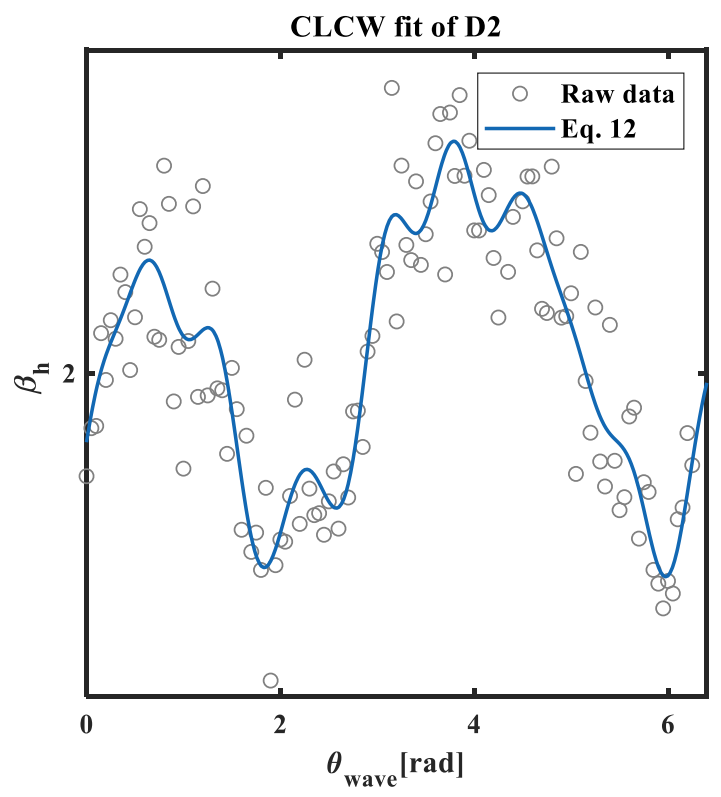

(d)

Figure 10. The fits and raw data of D2 model a) The mean parameter of LLCL, R-squared: 0.959, b) The square of the standard deviation parameter of LLCL, R-squared: 0.997, c) The scale parameter of CLCW, R-squared: 0.979, and d) The shape parameter of CLCW, R-squared: 0.828

The main scope of this research as mentioned before is to provide the designers with the joint probability of metocean parameters. The models are expected to generate a series of data which are likely to occur realistically. Monte-Carlo methods are usually used to generate pseudo-random samples from complex distributions [26, 46]. Latin Hypercube Sampling (LHS) as a more efficient way can also be applied to generate samples $[\underline{47}, \underline{48}]$. Both of these methods were used herein to validate the JPDFs. The samples generated by the $\mathrm{MC}$ are compared versus the hindcast data to test the accuracy of the models. To better illustrate the correspondence of model versus hindcast variables, the histograms of generated samples are compared in Figure 11. The samples of $\left(U_{w}, H_{s}, T_{p}\right)$ predicted by D1 and $\theta_{\text {wind }}, \theta_{\text {wave }}$ and $\Delta \theta$ generated respectively by D2, D3 and D4 as shown are in good accordance. The RMSE, as a popular goodness of fit test, was also utilized to check the results. The 3-variate samples of data were generated from D1-D4 distributions by MC method. Then the accuracy of the fits was evaluated by the RMSE (Root Mean Square Error) statistic [46]. Two sets of this statistic were computed for the models. The RMSE of the whole JPDFs 
522 are listed in Table 1. Then the RMSE of pairs of variables are reported in Table 2. As can be seen, the low 523 values (near zero) show adequate accuracy of the model.

\section{Table 4.}

\section{The RMSE of the JPDFs}

\begin{tabular}{ccccc}
\hline & D1 & D2 & D3 & D4 \\
\hline RMSE & 0.0151 & 0.0082 & 0.0065 & 0.0062 \\
\hline
\end{tabular}

526

\section{Table 5.}

528 The RMSE of pairs of variables

\begin{tabular}{ccccc}
\hline & & $U_{w}$ & $H_{s}$ & $T_{p}$ \\
\hline $\mathrm{D} 1\left(U_{w}, H_{s}, T_{p}\right)$ & $U_{w}$ & & 0.0216 & 0.0207 \\
& $H_{s}$ & & & 0.0131 \\
\hline $\mathrm{D} 2\left(\theta_{\text {wave }}, H_{s}, T_{p}\right)$ & $\theta_{\text {wave }}$ & & 0.0104 & 0.0129 \\
& $H_{s}$ & & & 0.0217 \\
\hline $\mathrm{D} 3\left(\theta_{\text {wind }}, U_{w}, H_{s}\right)$ & $\theta_{\text {wind }}$ & 0.0053 & 0.0119 & \\
\hline $\mathrm{D} 4\left(\Delta \theta, U_{w}, H_{s}\right)$ & $U_{w}$ & & 0.0217 & \\
\hline
\end{tabular}




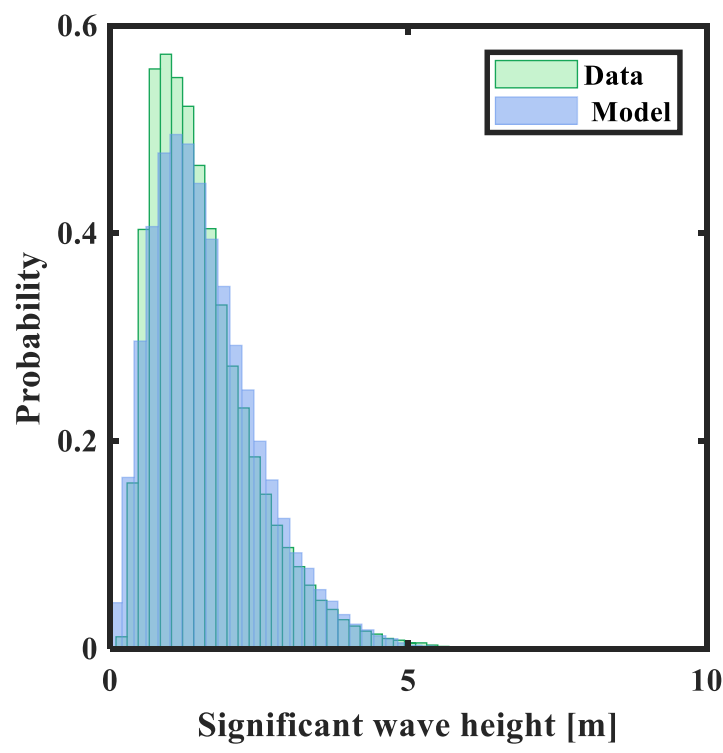

(a)

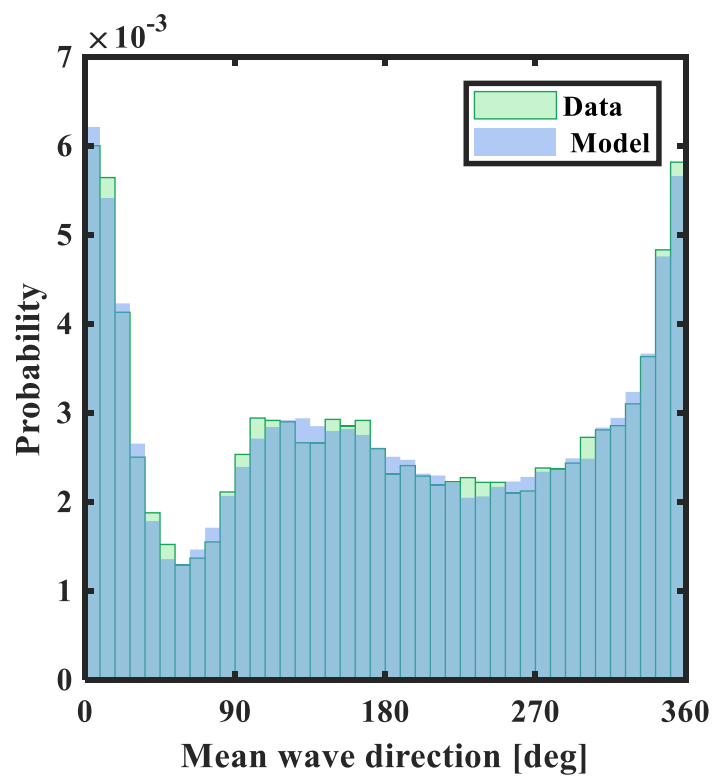

536 537

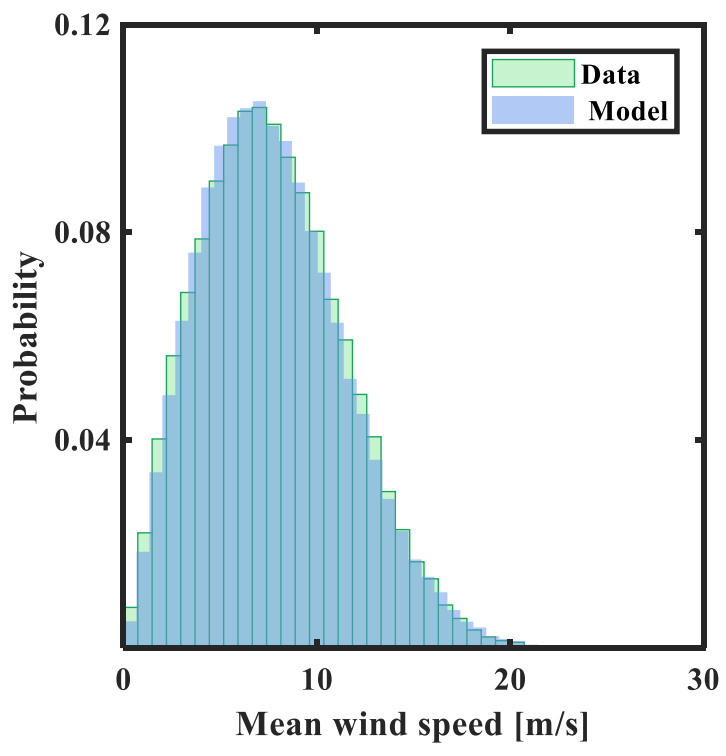

(b)

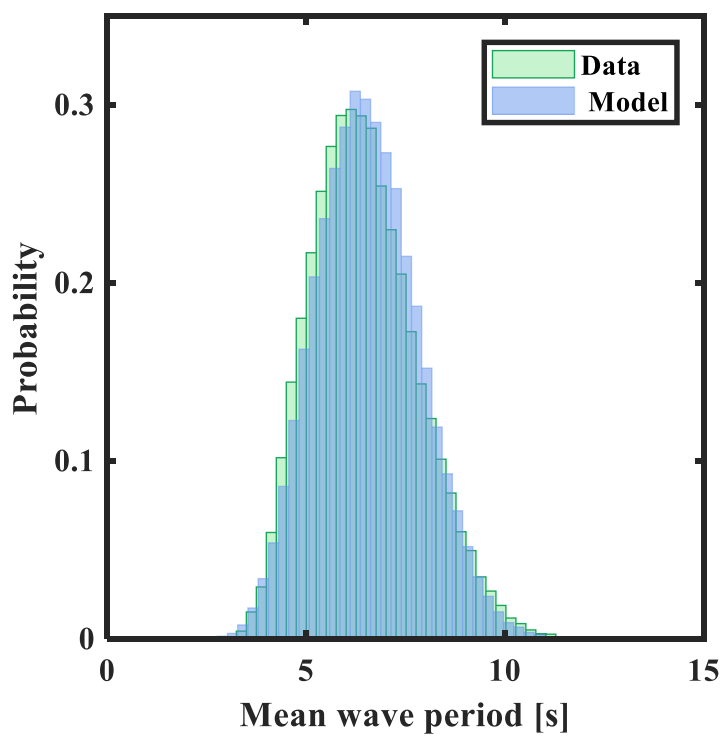

(d) 


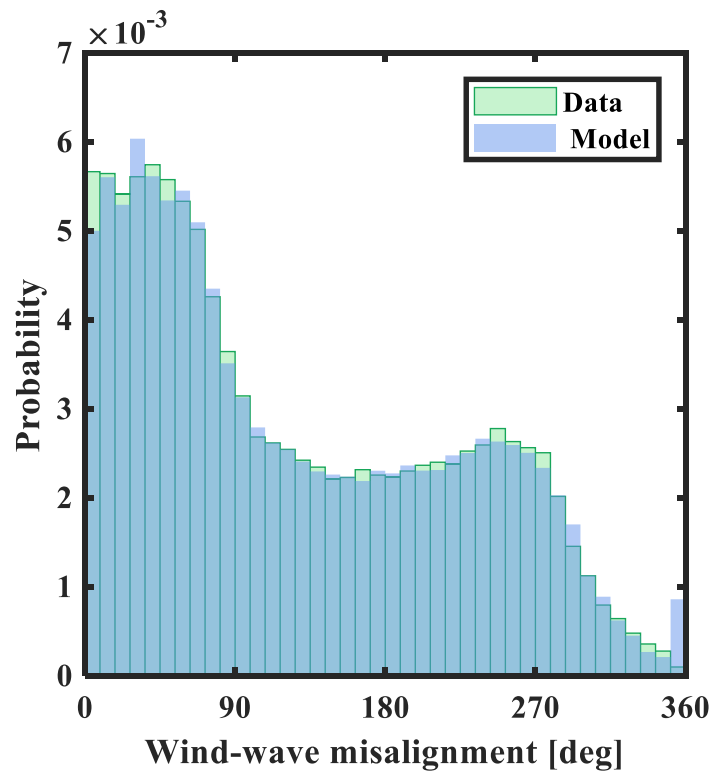

(e)

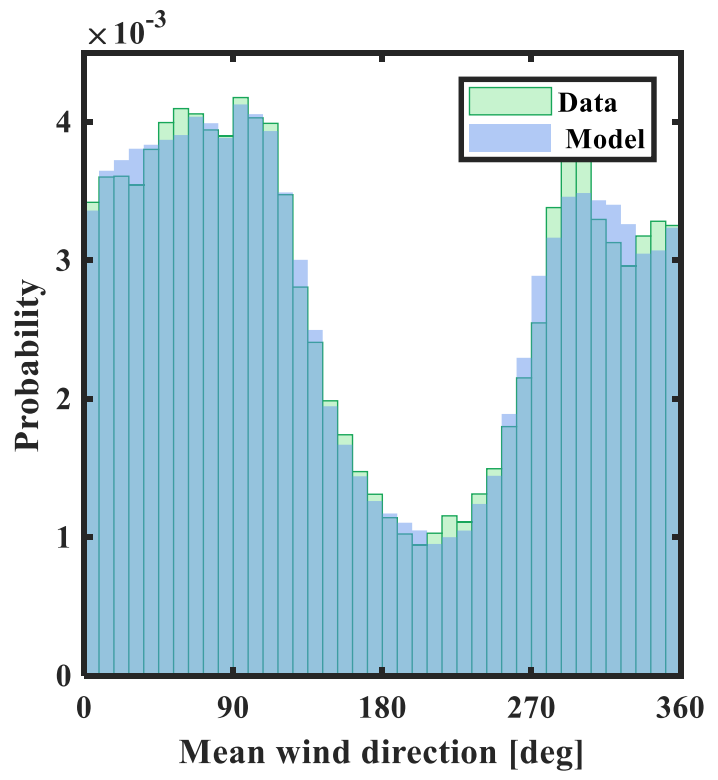

(f)

540 Figure 11. The generated vs. hindcast data: a) $U_{w}$ from D1, b) $H_{s}$ from D1, c) $T_{p}$ from D1, d) $\theta_{\text {wave }}$ from $\mathrm{D} 2, \mathrm{e}) \theta_{\text {wind }}$ from D3, f) $\Delta \theta$ from D4.

\section{Discussion and investigation of extreme values}

To discuss the results of implemented IFORM on the combinations of circular and linear metocean conditions, two sets of comparisons have been made. First, the maximum values of linear variables extracted from extreme contours of four JPMs (i.e., D1-D4 models) are compared. Then the extreme contours for two sets of variables from different JPMs are chosen to be contrasted.

\subsection{Discussion on the extreme values in contrast to marginal distributions}

According to the results of applying the environmental contours method on the JPMs D1-D4 models (

Table 2), the contours where the extreme value of each linear variable occurs were selected to compare the extremes extracted from different JPMs. The environmental contours associated with the highest value of parameters as defined and explained in Section 6, were compared to the extreme values associated with a 50-year MRP from marginal distributions in Table 6. It can be seen that the values of $H_{s}$ and $U_{w}$ are in close ranges for the D1 model, $\left(U_{w}, H_{s}, T_{p}\right)$, and marginal distributions. However, the extreme contours for 
of marginal distributions. While in the D4 model, $\left(\Delta \theta, U_{w}, H_{s}\right)$, the extreme values are near the marginal 556 ones.

\section{Table 6.}

The extreme values for the 50-year return period from marginal distribution and D1-D4 JPMs for linear 560 variables.

\begin{tabular}{lccc}
\hline \multicolumn{1}{c}{ Parameter } & $U_{w}$ & $H_{s}$ & $T_{p}$ \\
\hline Marginal distribution & $26.56 \mathrm{~m} / \mathrm{s}$ & $6.35 \mathrm{~m}$ & $15.33 \mathrm{~s}$ \\
D1 $\left(U_{w}, H_{s}, T_{p}\right)$ & $26 \mathrm{~m} / \mathrm{s}$ & $7.02 \mathrm{~m}$ & $11.04 \mathrm{~s}$ \\
D2 $\left(\theta_{\text {wave }}, H_{s}, T_{p}\right)$ & - & $8.4 \mathrm{~m}$ & $12.2 \mathrm{~s}$ \\
D3 $\left(\theta_{\text {wind }}, U_{w}, H_{s}\right)$ & $28.8 \mathrm{~m} / \mathrm{s}$ & $8.18 \mathrm{~m}$ & - \\
$\mathrm{D} 4\left(\Delta \theta, U_{w}, H_{s}\right)$ & $27.4 \mathrm{~m} / \mathrm{s}$ & $7.1 \mathrm{~m}$ & - \\
\hline
\end{tabular}

\subsection{Comparison of extreme contours}

The extreme contours of specified variables from different JPMs are compared and evaluated. The extreme values from different JPMs show considerably different values. Reviewing the process of building this series of JPDFs may help to explain such differences. To find the parameters of JPDFs, the underlying data of each JPDF is at first sorted in the form of tables with specified bin numbers; then the prescribed function forms are fitted to the distribution parameters. Researchers have applied the D1 model to find the extreme sea states associated with specified MRPs [38]. In the case of the D1 model, which is the JPDF of wind speed, wave height, and wave period, there is an increasing monotonic relation between wind speed, wave height, and period.

Moreover, the definition of JPDF is somehow based on the physical relation of $U_{w}, H_{s}$, and $T_{p}$, while in the case of D2-D4 models, where the primary variable which has the marginal distribution is a circular variable, there is not inherently a monotonic relation between the increases of parameters. Since the winds and waves coming from different directions usually have various sources of generation, the data in these distributions in each bin of sorted data may come from different sources and show different behaviours; and thus, different parameter distributions can be fitted to them. The data in a specified bin may maintain a higher mean value; and thus, a Weibull distribution with much higher parameters than that of the aggregate data is fitted to this subpopulation. This may lead to a higher probability prediction for these bins. Vanem has recently investigated the effect of data sub-sampling on the resulted contours to account for seasonality 
581 located in higher sea states or lower sea states, i.e. the contours for harsher seasons are much higher than 582 contours of seasons with calmer weather. However, the contours can be moderated by some methods to be 583 applied for practical applications which are out of the scope of the current research.

584 The definition of distributions and the order of marginal-conditional distributions affect the way the 585 data is sorted and binned and the distributions fitted to each bin. This definition influences the shape of the 586 ES, and thus the final extreme contour is highly dependent on the definition of distributions. To further 587 investigate the issue, the most extreme contours from different distributions are compared in Figure 12. As 588 can be seen, the contours which are frequent in different distributions (D1-D4 models) are chosen. First, 589 the extreme values of contours of $U_{w}-H_{s}$ from the D1 model, D3 model, and D4 model are plotted in Figure 590 12a. The contour of $\theta_{\text {wind }}=159^{\circ}$ derived from the ES of the D3 model $\left(\theta_{\text {wind }}, U_{w}, H_{s}\right)$ is located in higher 591 values, as mentioned in Table 6. The second highest value is associated with $\Delta \theta=68^{\circ}$ from the ES of D4 592 model $\left(\Delta \theta, U_{w}, H_{s}\right)$. The lowest value locates on the contour associated with D1 model $\left(U_{w}, H_{s}, T_{p}\right)$.

593 Figure $10 \mathrm{~b}$ also shows the results of comparison of contours of $H_{s}-T_{p}$ from the D1 and D2. The extreme 594 value of the combination of $H_{s}-T_{p}$ derived from the D1 model $\left(U_{w}, H_{s}, T_{p}\right)$ which is located at $595 U_{w}=26 \mathrm{~m} / \mathrm{s}$ is a limited area, while the contour of $H_{s}-T_{p}$ derived from the D2 model (JPDF of $\theta_{\text {wave }}, H_{s}$ 596 and $T_{p}$ ) is quietly extended in a big area of wave height and periods, where the $\theta_{\text {wave }}=106^{\circ}$. This can be 597 explained by a look at the difference of the form of ES of D1 and D2 models. The ES created by D1 model 598 is physically interpreted by the inherent nature of wind and waves and has usually shown the fastest winds 599 to be accompanied by higher waves. The generation of waves is dependent on the existence of wind. 600 However, the problem of concurrency and the definition of wind seas and swells can be taken into account. 601 It is clear that the sea states become more severe as higher winds below; and hence, it can be accepted that 602 high amounts of wave are concurrent with limited conditions of wind speed. The ES created by the JPM of 603 D1 model $\left(U_{w}, H_{s}, T_{p}\right)$ expands in a big area of $\left(H_{s}, T_{p}\right)$ in the low values of $U_{w}$, but the cross-sectional 604 area reduces with the increase of $U_{w}$, as can be seen in Figure 6a the number of data points also decreases 605 as $U_{w}$ increases. In the case of directional variables, on the other hand, there is no physical meaning between 606 the direction and wind and wave linear characteristics. Wind and waves generally may come from any 607 direction without any limitations on their speeds and heights, respectively. The distributions which create 
608 the contours rely on data in bins associated with each direction. The spreading of data in each bin of 609 direction as in (D2-D4 models) is more varied than its diversity in the bins of wave period as in D1 model. 610 This can also be explained by the physical limitations on the wave and wind characteristics like wave 611 steepness. Accordingly, the contours of wave and wind created by directional considerations cover a wide 612 span of wind and wave linear characteristics. As can be seen in Figure 7-Figure 12, the cross-section of the 613 ESs associated with D2-D4 models which contain directional variables is then extended along the direction 614 axis with more or less continuous densities spread all over the axis. 615

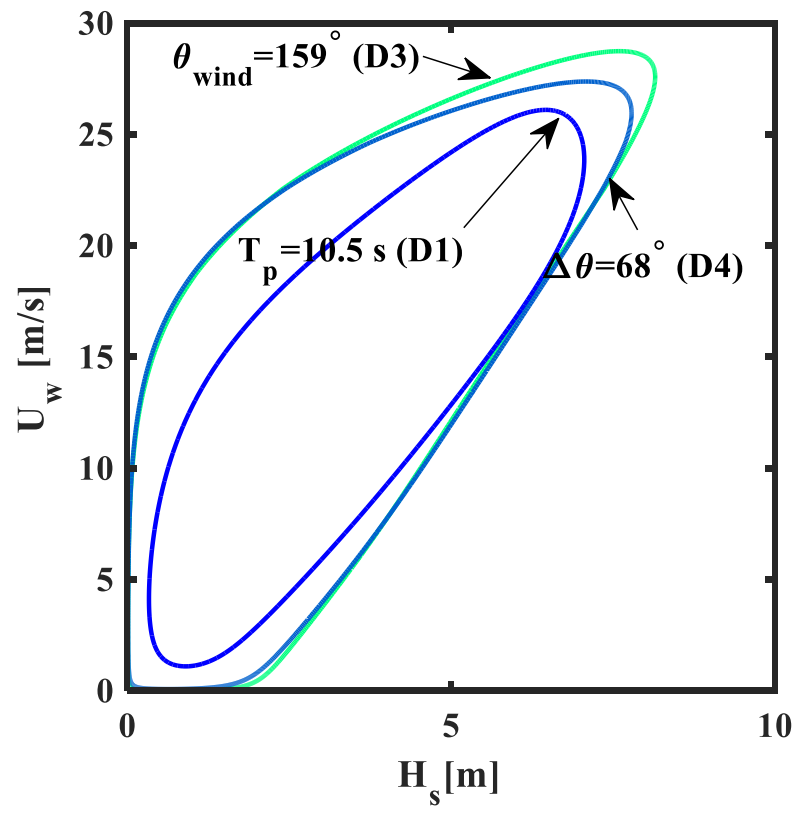

(a)

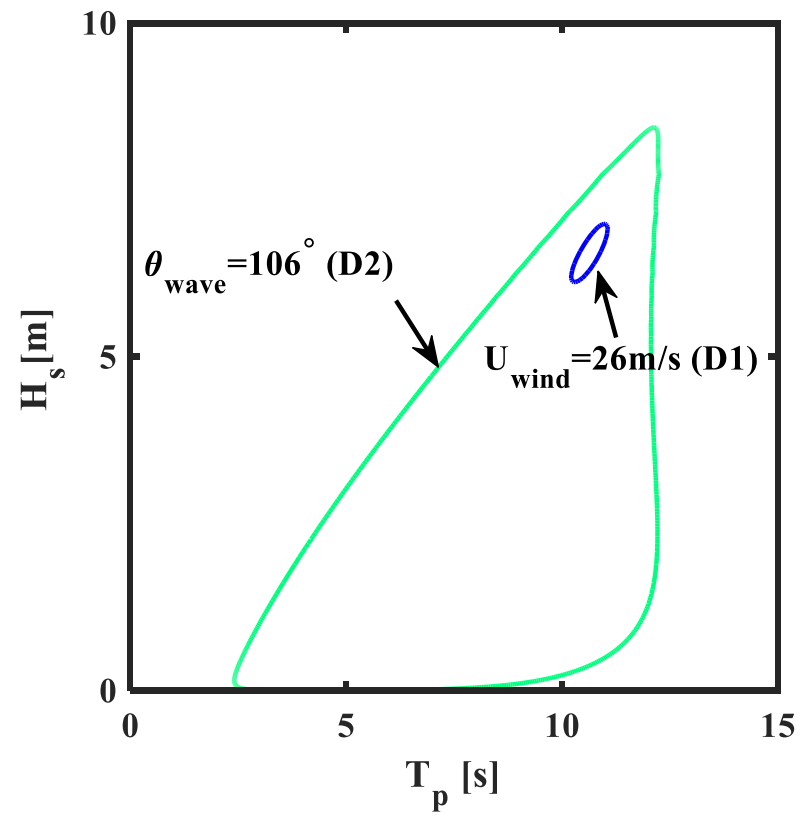

(b)

618 Figure 12. The highest contours created by different distributions. a) contours of $\left(U_{w}-H_{s}\right)$ b) contours of ( $\left.H_{s}-T_{p}\right)$

\section{Conclusion}

The present research was conducted to reach to an understanding of the concurrence of metocean 622 conditions in the HyWind Scotland site, Scotland. To achieve this, four combinations of metocean parameters were selected, and their JPDFs were created. Then, the ESs (environmental surfaces) were

624 developed for these combinations of parameters utilizing the IFORM and the CMA. Analysing the surfaces 625 and their underlying contours, the subsequent outcomes can be comprehended: 
- The traditional methods of design environment choosing suggest the use of rose diagrams and directional density plots to find the direction of wind or wave in which the structure will be damaged more. This research proposes the use of ESs created considering the directionality of metocean parameters to find the design direction.

- Comparison of the results shows that using just the rose plot or marginal PDF of directional data for prediction of the design wind or wave direction may lead to choosing the design direction which is not associated with the most extreme sea states, since the extreme waves or winds may come from directions which are not frequent in the site. Thus, it is necessary to utilize approaches which consider the concurrency of metocean parameters to forecast the combinations with higher precision.

- The shape and size of 3D ESs which account for directionality, are almost the same as the shape of their underlying ECs in 2D. e.g., The contours developed by D2, which is the JPDF of wave parameters $\left(\theta_{\text {wave }}, H_{s}, T_{p}\right)$ are similar to contours of the omnidirectional form of $\left(H_{s}, T_{p}\right)$.

- The misalignment of wind and waves in the HyWind Scotland site is remarkable so that the most extreme winds and waves may act in quite the opposite directions. That may happen due to the nature of waves and winds affected by different metocean processes in the North Sea.

In conclusion, the results show that the most extreme environmental conditions usually are concurrent with the directions which are not frequent. The analysis of concurrency of extreme metocean conditions through the ESs of directional variables reveals that the extreme values are dependent on the distributions on which ESs are based. Since ESs are dependent on the order of parameters in each JPDF, these distributions should be chosen based on the relative importance of metocean variables in the design process. 


\section{Appendix}

649 Table A1.

650 Wave direction distribution.

651

652

\begin{tabular}{llll}
\hline \multirow{2}{*}{ No. of component } & \multicolumn{3}{c}{ Parameters of Mixture of von-Mises Fischer } \\
\cline { 2 - 4 } & $\alpha$ & $\mu$ & $\kappa$ \\
\hline 1 & 0.166 & -1.464 & 1.975 \\
2 & 0.181 & 0.111 & 11.114 \\
3 & 0.193 & 1.887 & 2.852 \\
4 & 0.203 & -0.321 & 2.537 \\
5 & 0.136 & 2.915 & 2.302 \\
6 & 0.120 & 2.686 & 1.711 \\
\hline
\end{tabular}

653 Table A2.

654 Wind direction distribution.

\begin{tabular}{llll}
\hline \multirow{2}{*}{ No. of component } & \multicolumn{3}{l}{ Parameters of Mixture of von-Mises Fischer } \\
\cline { 2 - 4 } & $\alpha$ & $\mu$ & $\kappa$ \\
\hline 1 & 0.081 & 0.343 & 1.595 \\
2 & 0.150 & 1.181 & 4.232 \\
3 & 0.107 & 3.031 & 1.435 \\
4 & 0.0961 & 0.721 & 1.631 \\
5 & 0.0721 & 0.238 & 1.343 \\
6 & 0.0768 & 0.215 & 1.272 \\
7 & 0.261 & 1.809 & 3.207 \\
8 & 0.156 & 0.682 & 2.957 \\
\hline
\end{tabular}

655

656

657

658

659

660

661

662

663

664

665

666 
667 Table A3.

668 Wind-wave misalignment distribution coefficients.

\begin{tabular}{llll}
\hline \multirow{2}{*}{ No. of component } & \multicolumn{3}{l}{ Parameters of Mixture of von-Mises Fischer } \\
\cline { 2 - 4 } & $\alpha$ & $\mu$ & $\boldsymbol{\kappa}$ \\
\hline 1 & 0.117 & 0.963 & 9.018 \\
2 & 0.115 & 0.464 & 27.316 \\
3 & 0.053 & 1.903 & 2.495 \\
4 & 0.104 & 1.012 & 7.775 \\
5 & 0.067 & 2.047 & 2.518 \\
6 & 0.069 & 0.135 & 131.492 \\
7 & 0.068 & 1.742 & 3.152 \\
8 & 0.053 & 1.737 & 2.8 \\
9 & 0.108 & 2.346 & 3.316 \\
10 & 0.108 & -2.991 & 3.68 \\
11 & 0.068 & 1.537 & 3.657 \\
12 & 0.069 & 1.614 & 3.192 \\
\hline
\end{tabular}

669

$670 \quad$ Table A4.

671 Parameters of the conditional distribution of wave period on wave height.

672

\begin{tabular}{ll}
\hline Parameter & Value \\
\hline$c_{1}$ & 0.35 \\
$c_{2}$ & 0.522 \\
$c_{3}$ & 1.43 \\
$d_{1}$ & 0.04326 \\
$d_{2}$ & 0.3926 \\
$d_{3}$ & -0.001 \\
\hline
\end{tabular}

673 Table A5.

674 Parameters of the conditional distribution of wave height on wind speed.

675

\begin{tabular}{ll}
\hline Parameter & Value \\
\hline$c_{1}$ & 0.0411 \\
$c_{2}$ & 1.536 \\
$c_{3}$ & 0.7539 \\
$d_{1}$ & 0.02 \\
$d_{2}$ & 1.755 \\
$d_{3}$ & 2.099 \\
\hline
\end{tabular}

676

677

678

679 
Table A6.

681 Parameters of the conditional distribution of wave height on wave direction.

\begin{tabular}{|c|c|c|}
\hline \multicolumn{2}{|c|}{ Parameter } & Value \\
\hline & $\alpha$ & $\beta$ \\
\hline $\mathrm{a}_{0}$ & 1.749 & 2.18 \\
\hline$a_{1}$ & -0.117 & 0.236 \\
\hline$b_{1}$ & -0.0 . & -0.093 \\
\hline $\mathrm{a}_{2}$ & -0.063 & -0.126 \\
\hline $\mathrm{b}_{2}$ & -0.124 & 0.167 \\
\hline$a_{3}$ & 0.106 & -0.021 \\
\hline$b_{3}$ & -0.101 & 0.037 \\
\hline $\mathrm{a}_{4}$ & 0.118 & 0.00 \\
\hline $\mathrm{b}_{4}$ & 0.045 & 0.023 \\
\hline$a_{5}$ & 0.008 & -0.004 \\
\hline $\mathrm{b}_{5}$ & 0.016 & 0.001 \\
\hline$a_{6}$ & 0.005 & 0.003 \\
\hline $\mathrm{b}_{6}$ & -0.052 & 0.026 \\
\hline $\mathrm{a}_{7}$ & 0.03 & -0.022 \\
\hline $\mathrm{b}_{7}$ & -0.019 & 0.02 \\
\hline $\mathrm{a}_{8}$ & 0.0001 & 0.02 \\
\hline $\mathrm{b}_{8}$ & 0.006 & -0.022 \\
\hline a9 & 0.007 & 0.003 \\
\hline $\mathrm{b}_{9}$ & -0.003 & 0.013 \\
\hline $\mathrm{a}_{10}$ & 0.011 & 0.014 \\
\hline$b_{10}$ & -0.006 & 0.004 \\
\hline
\end{tabular}

682

683

684

685

686

687

688

689

690

691

692

693

694 


\section{Table A7.}

696 Parameters of the conditional distribution of wind speed on wind direction.

\begin{tabular}{lll}
\hline Parameter & \multicolumn{2}{c}{ Value } \\
\hline & $\alpha$ & $\beta$ \\
$\mathrm{a}_{0}$ & 8.376 & 2.18 \\
$\mathrm{a}_{1}$ & 1.09 & 0.236 \\
$\mathrm{~b}_{1}$ & 0.476 & 0.069 \\
$\mathrm{a}_{2}$ & -0.28 & -0.126 \\
$\mathrm{~b}_{2}$ & -0.547 & -0.014 \\
$\mathrm{a}_{3}$ & -0.13 & -0.021 \\
$\mathrm{~b}_{3}$ & 0.227 & 0.021 \\
$\mathrm{a}_{4}$ & 0.095 & -0.006 \\
$\mathrm{~b}_{4}$ & 0.098 & 0.033 \\
$\mathrm{a}_{5}$ & 0.772 & 0.004 \\
$\mathrm{~b}_{5}$ & 0.004 & 0.012 \\
$\mathrm{a}_{6}$ & 0.029 & 0.032 \\
$\mathrm{~b}_{6}$ & -0.11 & $1.62 \mathrm{e}-05$ \\
$\mathrm{a}_{7}$ & -0.007 & -0.011 \\
$\mathrm{~b}_{7}$ & -0.066 & -0.009 \\
$\mathrm{a}_{8}$ & -0.047 & -0.002 \\
$\mathrm{~b}_{8}$ & 0.063 & 0.007
\end{tabular}

697

698 Table A8.

699 Parameters of the conditional distribution of wind speed on wind-wave misalignment.

\begin{tabular}{lll} 
Parameter & \multicolumn{2}{c}{ Value } \\
\hline & $\alpha$ & $\beta$ \\
$a_{0}$ & 8.107 & 2.249 \\
$a_{1}$ & -0.717 & 0.134 \\
$b_{1}$ & 0.834 & -0.029 \\
$a_{2}$ & -0.396 & 0.016 \\
$b_{2}$ & 1.077 & 0.058 \\
$a_{3}$ & -0.121 & 0.014 \\
$b_{3}$ & 0.708 & 0.023 \\
$a_{4}$ & 0.025 & 0.038 \\
$b_{4}$ & 0.245 & -0.016 \\
$a_{5}$ & 0.057 & 0.045 \\
$b_{5}$ & 0.133 & -0.008 \\
$a_{6}$ & -0.043 & 0.016 \\
$b_{6}$ & 0.248 & -0.033 \\
$a_{7}$ & -0.031 & 0.006 \\
$b_{7}$ & 0.245 & -0.004 \\
$a_{8}$ & 0.029 & 0.027 \\
$b_{8}$ & 0.182 & -0.008 \\
\hline
\end{tabular}




\section{References}

702 [1] Karimirad M, Michailides C, Nematbakhsh A. Offshore Mechanics: Structural and Fluid Dynamics

703

704

705

706

707

708

709

710

711

712

713

714

715

716

717

718

719

720

721

722

723

724

725

726

727

728

729

730

731

732

733

734

735

736

737

738

739

740

741

742

743

744

745

for Recent Applications: John Wiley \& Sons; 2018.

[2] Naess A, Moan T. Stochastic dynamics of marine structures: Cambridge University Press; 2012.

[3] DNVGL-RP-C205. Environmental conditions and environmental loads. Det Norske Veritas group, Norway. 2017.

[4] NORSOK-N-003. NORSOK Standard N-003:2017: Actions and action effects. NORSOK, Norway. 2017.

[5] API-RP-2A-WSD. Recommended Practice for planning, designing, and constructing fixed offshore platforms-working stress design. 21st ed, Washington, DC: API Publishing Services. 2005. [6] ISO I. 19901-1: 2005, Petroleum and natural gas industries-specific requirements for offshore structures-Part 1: Metocean design and operating conditions. British Standards Institute. 2005. [7] IEC61400-3. Wind Turbines-Part 3: Design requirements for offshore wind turbines. International Electrotechnical Commission. 2009.

[8] ISO19901-1. Petroleum and natural gas industries. Specific requirements for offshore structures. Part 1: Metocean design and operating considerations. First edition International Standards Organisation. 2015.

[9] ABS FWT. USA: American Bureau of Shipping Corporate Offshore Technology. Renewables. 2012. [10] Bitner-Gregersen EM. Joint met-ocean description for design and operations of marine structures. Applied Ocean Research. 2015;51:279-92.

[11] Jonathan P, Ewans K, Forristall G. Statistical estimation of extreme ocean environments: The requirement for modelling directionality and other covariate effects. Ocean Engineering. 2008;35:121125.

[12] Forristall GZ. On the use of directional wave criteria. Journal of waterway, port, coastal, and ocean engineering. 2004;130:272-5.

[13] Karimirad M, Michailides C. V-shaped semisubmersible offshore wind turbine subjected to misaligned wave and wind. Journal of Renewable and Sustainable Energy. 2016;8:023305.

[14] Valamanesh V, Myers A, Arwade S. Multivariate analysis of extreme metocean conditions for offshore wind turbines. Structural Safety. 2015;55:60-9.

[15] Wei K, Arwade SR, Myers AT, Valamanesh V. Directional effects on the reliability of nonaxisymmetric support structures for offshore wind turbines under extreme wind and wave loadings. Engineering Structures. 2016;106:68-79.

[16] Valamanesh V, Myers aT, Arwade SR. Multivariate analysis of extreme metocean conditions for offshore wind turbines. Structural Safety. 2015;55:60-9.

[17] Schmidt B, Hansen M, Marx S. Directional dependence of extreme load parameters for offshore wind turbines. The Twenty-fifth International Ocean and Polar Engineering Conference: International Society of Offshore and Polar Engineers; 2015.

[18] Hildebrandt A, Schmidt B, Marx S. Wind-wave misalignment and a combination method for direction-dependent extreme incidents. Ocean Engineering. 2019;180:10-22.

[19] Lutes LD, Winterstein SR. A dynamic inverse FORM method: design contours for load combination problems. Probabilistic Engineering Mechanics. 2016;44:118-27.

[20] Chai W, Leira BJ. Environmental contours based on inverse SORM. Marine Structures. 2018;60:3451.

[21] Haselsteiner AF, Ohlendorf J-H, Wosniok W, Thoben K-D. Deriving environmental contours from highest density regions. Coastal Engineering. 2017;123:42-51. 
746

747

748

749

750

751

752

753

754

755

756

757

758

759

760

761

762

763

764

765

766

767

768

769

770

771

772

773

774

775

776

777

778

779

780

781

782

783

784

785

786

787

788

789

790

791

[22] Huseby AB, Vanem E, Natvig B. A new approach to environmental contours for ocean engineering applications based on direct Monte Carlo simulations. Ocean Engineering. 2013;60:124-35.

[23] Vanem E. 3-dimensional environmental contours based on a direct sampling method for structural reliability analysis of ships and offshore structures. Ships and Offshore Structures. 2019;14:74-85. [24] Vanem E, Hafver A, Nalvarte G. Environmental contours for circular-linear variables based on the direct sampling method. Wind Energy. 2019.

[25] Haghayeghi ZS, Ketabdari MJ. A long-term joint probability model for metocean circular and linear characteristics. Applied Ocean Research. 2018;75:143-52.

[26] Horn J-T, Bitner-Gregersen E, Krokstad JR, Leira BJ, Amdahl J. A new combination of conditional environmental distributions. Applied Ocean Research. 2018;73:17-26.

[27] Soukissian TH. Probabilistic modeling of directional and linear characteristics of wind and sea states. Ocean Engineering. 2014;91:91-110.

[28] Montes-Iturrizaga R, Heredia-Zavoni E. Reliability analysis of mooring lines using copulas to model statistical dependence of environmental variables. Applied Ocean Research. 2016;59:564-76.

[29] Manuel L, Nguyen PTT, Canning J, Coe RG, Eckert-Gallup AC, Martin N. Alternative approaches to develop environmental contours from metocean data. Journal of Ocean Engineering and Marine Energy. 2018;4:293-310.

[30] Montes-Iturrizaga R, Heredia-Zavoni E. Environmental contours using copulas. Applied Ocean Research. 2015;52:125-39.

[31] Silva-González F, Heredia-Zavoni E, Montes-Iturrizaga R. Development of environmental contours using Nataf distribution model. Ocean Engineering. 2013;58:27-34.

[32] Edwards SJ, Coe RG. The effect of environmental contour selection on expected wave energy converter response. Journal of Offshore Mechanics and Arctic Engineering. 2019;141.

[33] Manuel L, Nguyen PT, Canning J, Coe RG, Eckert-Gallup AC, Martin N. Alternative approaches to develop environmental contours from metocean data. Journal of Ocean Engineering and Marine Energy. 2018;4:293-310.

[34] Dee DP, Uppala SM, Simmons AJ, Berrisford P, Poli P, Kobayashi S, et al. The ERA-Interim reanalysis: configuration and performance of the data assimilation system. Quarterly Journal of the Royal Meteorological Society. 2011;137:553-97.

[35] Imani H, Kamranzad B. Evaluation of ERA-interim wave characteristics in southern caspian sea.

12th International Conference on Coasts, Ports and Marine Structures. Tehran, Iran2016.

[36] Gelman A, Stern HS, Carlin JB, Dunson DB, Vehtari A, Rubin DB. Bayesian data analysis:

Chapman and Hall/CRC; 2013.

[37] Rosenblatt M. Remarks on a Multivariate Transformation. Ann Math Statist. 1952;23:470-2.

[38] Li L, Gao Z, Moan T. Joint Distribution of Environmental Condition at Five European Offshore Sites for Design of Combined Wind and Wave Energy Devices. Journal of Offshore Mechanics and Arctic Engineering. 2015;137:031901--16.

[39] Jammalamadaka SR, Sengupta A. Topics in circular statistics: world scientific; 2001.

[40] Pewsey A, Neuhäuser M, Ruxton GD. Circular statistics in R: Oxford University Press; 2013.

[41] Masseran N, Razali AM, Ibrahim K, Latif MT. Fitting a mixture of von Mises distributions in order to model data on wind direction in Peninsular Malaysia. Energy Conversion and Management.

2013;72:94-102.

[42] Carta JA, Bueno C, Ramírez P. Statistical modelling of directional wind speeds using mixtures of von Mises distributions: Case study. Energy conversion and management. 2008;49:897-907.

[43] Oliveira M, Crujeiras RM, Rodríguez-Casal A. NPCirc: An R package for nonparametric circular methods. Journal of Statistical Software. 2014;61:1-26. 
792 [44] Hornik K, Grün B. movMF: An R Package for Fitting Mixtures of von Mises-Fisher Distributions. 793 Journal of Statistical Planning and Inference. 2012;143:992-9.

794 [45] Mardia KV, Jupp PE. Directional statistics: John Wiley \& Sons; 2009.

795 [46] Lin Y, Dong S. Wave energy assessment based on trivariate distribution of significant wave height, 796 mean period and direction. Applied Ocean Research. 2019;87:47-63.

797 [47] Low YM. A variance reduction technique for long-term fatigue analysis of offshore structures using 798 Monte Carlo simulation. Engineering Structures. 2016;128:283-95.

799 [48] Gao Y, Low YM. An efficient importance sampling method for long-term fatigue assessment of 800 deepwater risers with time domain analysis. Probabilistic Engineering Mechanics. 2016;45:102-14. 801 [49] Vanem E. A simple approach to account for seasonality in the description of extreme ocean 802 environments. Marine Systems \& Ocean Technology. 2018;13:63-73.

803 [50] Montes-Iturrizaga R, Heredia-Zavoni E. Assessment of uncertainty in environmental contours due to 804 parametric uncertainty in models of the dependence structure between metocean variables. Applied Ocean 805 Research. 2017;64:86-104.

806 [51] Silva-González F, Vázquez-Hernández A, Sagrilo L, Cuamatzi R. The effect of some uncertainties 807 associated to the environmental contour lines definition on the extreme response of an FPSO under 808 hurricane conditions. Applied Ocean Research. 2015;53:190-9. 